\title{
INDIVIDUAL DIFFERENCES IN SEMANTIC PROCESSING
}

Individual differences in combinatorial semantic processing:

Skilled comprehension facilitates complement coercion during sentence comprehension

Clinton L. Johns ${ }^{\mathrm{a}}$, Luca Campanelli ${ }^{\mathrm{a}, \mathrm{b}}$, Dave Kush ${ }^{\mathrm{a}, \mathrm{c}}$, Nicole Landi ${ }^{\mathrm{a}, \mathrm{d}, \mathrm{e}}$, and Julie A. Van Dyke ${ }^{\mathrm{a}, \mathrm{e}}$

${ }^{a}$ Haskins Laboratories, 300 George St., Suite 900, New Haven, CT, 06511, U.S.A.

${ }^{\mathrm{c}}$ The Graduate Center of the City University of New York, 365 Fifth Avenue, Rm. 7107, New

York, N.Y. 10016-4309, U.S.A.

${ }^{\mathrm{c}}$ Department of Language and Literature, Norwegian University of Science and Technology, NO-7491 Trondheim, Norway

${ }^{\mathrm{d}}$ Department of Psychological Sciences, University of Connecticut, 406 Babbidge Road, Unit 1020, Storrs, CT, 06269-1020, U.S.A.

${ }^{\text {e }}$ Connecticut Institute for the Brain and Cognitive Sciences, University of Connecticut, Storrs, CT 06269-1272, USA

Please address correspondence to:

Clinton L. Johns, Ph.D.

Phone: 203-865-6163 x240

Email: Clinton.Johns@HaskinsLabs.org 


\begin{abstract}
Although poor comprehenders struggle with word-level semantics, little is known about how they negotiate "higher-level" combinatorial semantic processing. This study investigated the relationship between reading comprehension ability and the processing of expressions requiring enriched semantic composition. Participants completed a battery of reading-related cognitive assessments, and we used a regression-based approach to calculate their comprehension ability relative to component skills. They also completed an eye movement study, reading sentences requiring enriched semantic processing, viz. complement coercion (e.g., Traxler, Pickering, \& McElree, 2002). Coercing verbs have semantic selectional requirements, i.e., their complements must denote an event (e.g., started the race); when coercing verbs combine with non-event complement NPs (e.g., started the book), an event-interpretation must be selected (e.g., reading), and processing difficulty results. Our study replicates and extends Frisson \& McElree (2008), which tested whether this cost reflected difficulty selecting an appropriate semantic interpretation, and reported that the number of alternative senses did not modulate processing effort - but did not account for their participants' reading ability. We predicted modulating effects of reading ability because poor readers are known to be sensitive to interference from competing, context-inappropriate semantic senses. Consistent with this, we found that poor readers processed coercing expressions more slowly than skilled readers. Further, skilled readers processed coerced expressions with few competing event-senses without apparent cost. This study shows, for the first time, that poor reader's online semantic processing difficulties extend beyond the level of lexical semantics, and that the coercion cost is at least partly attributable to semantic sense selection.
\end{abstract}




\section{INDIVIDUAL DIFFERENCES IN SEMANTIC PROCESSING}

It is well known that comprehension ability varies across readers. Some differences can be attributed to individual variation in lexical (e.g., Perfetti \& Hart, 2001, 2002) and syntactic (e.g., King \& Just, 1991; Long \& Prat, 2008; MacDonald \& Christiansen, 2002; Pearlmutter \& MacDonald, 1995; cf. James, Fraundorf, Lee, \& Watson, 2018) processes which, together, provide the minimum information necessary for interpreting sentence-level meanings (Jackendoff, 2002). However, this information is not sufficient for the accurate interpretation of some types of text. For example, there are many linguistic expressions that require semantic processing above and beyond the products of lexical and syntactic analysis - processing that is typically related to "enriched semantic composition" (Pelletier, 1994; see also McElree, Traxler, Pickering, Seeley, \& Jackendoff, 2001; Piñango, Zurif, \& Jackendoff, 1999). Little is known about reader-level variability specific to enriched semantic composition - an empirical gap that takes on urgency in light of evidence that poor comprehension may be related to semantic processing deficits (for review see Landi \& Ryherd, 2017). The goal of this study is to assess the possibility that individual differences in combinatorial semantic compositional processes are related to comprehension difficulty. To this end, we focused our investigation on a particular type of semantic composition - complement coercion - which affords the possibility of assessing individual differences in semantic processing independently of syntactic knowledge.

It is common, in both speech and text, for verbs to place various semantic restrictions on the types of entities with which they combine (e.g., animacy restrictions on arguments). In most cases, violating these restrictions produces obviously incomprehensible results (e.g., "Mary congealed"), or results which can only be understood in metaphorical terms (e.g., "The couch swallowed the little girl."). However, there are also cases in which the semantic restrictions of the verb can facilitate interpretation of otherwise anomalous expressions by cuing specific 
elaborations that reconcile mismatching semantic information. For example, the semantic restrictions for a verb like finish requires its complement noun phrase to denote a temporallybounded event (Jackendoff, 1997; Pustejovsky, 1991, 1995, 2011). Consider the following:

(1) The man finished running the race.

(2) The man finished the race.

(3)* The man finished the cake.

(4) The man finished [eating] the cake.

This requirement is met in (1), allowing basic compositional operations to link finished and the event running the race to form a sensible verb phrase. The requirement is also met in (2), in which the complement noun phrase the race denotes the same event. In (3), however, the restriction is violated: the complement NP the cake denotes an entity, not an event. In such cases, the semantic type violation is thought to initiate elaborative processes that "enrich" the meaning of the NP by imputing to it an event-sense that is not itself explicit in the text, here corresponding to (4).

This process, by which readers force the semantic type of a mismatching input to match combinatorial semantic requirements, has been referred to as coercion (Jackendoff, 2002; Moens \& Steedman, 1988; Pustejovsky, 2011; for a review see Lauwers \& Willems, 2011). Since this kind of semantic mismatch does not interact with the number or type of syntactic operations during parsing, coercion is thought to reflect the independent operation of semantic processes (Pylkkänen, 2008; Pylkkänen \& McElree, 2006, 2007). Importantly, previous research has shown that the coercion-related operations incur measurable processing costs. Sentences like (3) have been shown to require more effort than sentences like (2) using both behavioral (Delogu, Crocker, \& Drenhaus, 2017; Katsika, Braze, Deo, \& Piñango, 2012; McElree et al., 2001; 
Traxler, Pickering, \& McElree, 2002) and neurophysiological paradigms (Baggio, Choma, van Lambalgen, \& Hagoort, 2009; Husband, Kelley, \& Zhu, 2011; Kuperberg, Choi, Cohn, Paczynski, \& Jackendoff, 2010; Pylkkänen \& McElree, 2007).

Although the cost associated with complement coercion is well-documented in collegiate readers, we are aware of no studies that have examined individual differences related to computing meaning in this way. In addition, the cognitive mechanism(s) that supports these operations remains a topic of debate. Traxler and colleagues (Traxler, McElree, Williams, \& Pickering, 2005) proposed that coercion requires a reader to engage in a sequence of operations recapitulated below:

(A) Initial access and basic composition: retrieve the complement NP's senses from the lexicon, initiating routine composition of the verb and its complement NP.

(B) Mismatch detection: when basic composition is insufficient, the incongruity between the verb's selectional requirements and the complement NP's semantic type prompts the execution of coercion.

(C) Inference/selection: impute (or select) a likely "event-sense" for the coerced predicate using available information (i.e., lexical, discourse, and world knowledge) about actions that are plausibly associated with the complement NP.

(D) Type-shifting and Integration: resolve the semantic mismatch by shifting the semantic type of the complement NP from entity-denoting to event-denoting, and incorporate the result into the sentence's semantic representation.

In principle, the coercion cost could reflect processing problems at any of these steps. However, previous investigations have largely dismissed the first two as potential points of origin for the coercion cost. The empirical basis for excluding these steps is straightforward: the acceptability, 
INDIVIDUAL DIFFERENCES IN SEMANTIC PROCESSING

plausibility, semantic co-occurrence, and cloze probability of coerced expressions, all of which might be expected to influence basic compositional processing in step A and/or attenuate (or eliminate) a mismatch in step B, appear to be unrelated to the cost of complement coercion (Frisson \& McElree, 2008; Kuperberg et al., 2010; McElree et al., 2006; Pylkkänen \& McElree, 2006; Traxler et al., 2002, 2005). In addition, eye tracking studies have overwhelmingly observed effects of complement coercion in measures that are typically associated with later stages of processing (e.g., regression path time, second pass time, total time), whereas initial lexical retrieval and the detection of semantic violations typically appear in earlier eye tracking measures (Pickering, Frisson, McElree, \& Traxler, 2004). Further, there are also studies showing that the neural signature of complement coercion is distinguishable from that associated with both semantic and syntactic violations (Baggio et al., 2010; Husband et al., 2011; Kuperberg et al., 2010; Pylkkänen \& McElree, 2007; cf. Delogu et al., 2017).

Accordingly, the difficulty associated with complement coercion is likely the result of processes related to (C) inference/selection or (D) integration. Traxler and colleagues (2005) propose that the coercion cost arises during the latter stage of processing, when an event-sense must be instantiated, after it is inferred or selected (see also Frisson \& McElree, 2008; McElree et al., 2006). Traxler and colleagues examined minimal passages in which the context provided by the first sentence was manipulated to influence either inference or type-shifting operations. In two experiments, the event corresponding to the coerced meaning was explicitly introduced in a preceding context sentence, with the goal of reducing or eliminating the cost associated with (C) inferential processing. However, the coercion cost persisted in both experiments. Two subsequent experiments targeted (D) integrative processes by instantiating the target coercion itself in the context sentence, so that a type-shifted, event-denoting sense of the complement 
INDIVIDUAL DIFFERENCES IN SEMANTIC PROCESSING

entity NP was available in the discourse representation. Traxler and colleagues found that this eliminated coercion-related processing difficulty and concluded that the coercion cost reflects the time and effort readers spend on the enriched compositional processing associated with typeshifting during integration. Subsequent studies using manipulations based on readers' world knowledge (e.g., ratings of the complement NP's thematic fit with the subject-verb combination in a coerced expression, as in Zarcone et al. (2017), which would ostensibly influence inferential processes in (C), are consistent with this conclusion.

However, although the coercion cost does not appear to be reducible to difficulty stemming from inferential processes, these studies did not address the possibility that it could derive from semantic ambiguity during sense selection, a situation which would affect processes associated with step (C), i.e., prior to final stage (D) type-shifting and integration. This possibility arises because many coerced expressions are inherently underspecified, such that many interpretations are possible. To illustrate, consider these examples, including (3) which is given again below:

(3) The man finished the cake.

(5) The birthday boy finished the cake.

(6) The pastry chef finished the cake.

The interpretation of these sentences is underspecified. For example, the man in (3) does not have to finish eating the cake, as we suggested above. Instead, he may have finished baking the cake, or decorating it, and so on. Crucially, sense selection capitalizes on information from the sentential context to restrict alternative senses, and sentences with greater semantic specification permit readers to resolve underlying ambiguity in favor of one interpretation among competing alternatives (e.g., Altmann \& Steedman, 1988; Pickering \& Traxler, 1998). Thus, although the 
INDIVIDUAL DIFFERENCES IN SEMANTIC PROCESSING

birthday boy in (5) is more likely to be eating a cake, the pastry chef in (6) is more likely to be baking or decorating it. Furthermore, as we will discuss below, the importance of contextual information to successful complement coercion may have particular consequences for individuals with low comprehension ability, as they may not benefit from context in the same way as skilled comprehenders (Nation \& Snowling, 1998) and may have difficulty deactivating context-inappropriate semantic senses of critical words during sentence processing (Gernsbacher \& Robertson, 1995; Gernsbacher, Varner, \& Faust, 1990; Long, Seely, \& Oppy, 1999).

At the time of this writing, the potential effect of ambiguity related to a word's semantic senses has received little attention, as the relation between the complement NP and the matrix verb is typically either highly constrained and relatively unambiguous (e.g., Traxler et al., 2005), or unconstrained and highly ambiguous (e.g., Delogu et al., 2017). However, in one of the only studies to directly consider it, Frisson and McElree (2008) manipulated the potential effect of semantic ambiguity using coercing verbs that were either associated with a single event-sense, or with multiple possible event-senses. In a norming study, they found that The student finished the essay was strongly biased to the event-sense of writing on $92 \%$ of trials. In contrast, The director started the script was weakly biased to a writing interpretation (35\% of the time), with eight other competing senses reported. In a subsequent eye tracking study, Frisson and McElree observed effects of semantic bias on the complement NP in late measures (second pass and total time), indicating that strongly biased sentences were easier to process. They also observed a coercion cost in both early (first pass time) and late measures. However, they did not observe any interaction between semantic bias and coercion, in either of the reported scoring regions (the complement NP and a spillover region) in any eye tracking measure. This pattern also emerged in a subsequent ERP study in which effects related to coercing expressions were not modulated 


\section{INDIVIDUAL DIFFERENCES IN SEMANTIC PROCESSING}

by semantic bias (Kuperberg et al., 2010; but see Schumacher, 2013, for an alternative interpretation of coercion-induced N400 effects). The results of these studies suggest that sense selection itself (step C) may not play a costly role in processing coercing expressions, and implicates downstream processes related to type-shifting and integration (step D) as the primary source of coercion costs.

Although most previous studies have concluded that difficulty in early processing stages is unlikely to account for coercion-specific costs, we believe it is crucial to consider potential individual differences in cognitive abilities that might affect these early steps in order to develop an understanding of the mechanisms that support enriched composition such as complement coercion. For example, with regard to initial decoding, retrieval, and basic compositional processes (i.e., step A), the primary importance of efficient decoding ability is well known (for reviews see, e.g., Stanovich, 1982; Shankweiler, 1989; Shankweiler et al., 1999). In addition, readers' sensitivity to lexical semantic information (e.g., semantic features or attributes of a lexical representation) affects retrieval during basic compositional processes. For example, readers' word knowledge modulates their ability to resolve semantic interference during both online parsing and offline comprehension (Van Dyke, Johns, \& Kukona, 2014). In this study, readers with high vocabulary scores experienced semantic interference earlier, with slower reading times during self-paced reading, while low vocabulary readers showed later effects, with lower comprehension accuracy than high vocabulary readers. Finally, with regard to detection of a semantic type mismatch (step B), word knowledge also correlates with readers' ability to detect certain types of semantic errors (e.g., categorization errors), with vocabulary scores positively correlated with accurate identification of semantic category members (e.g., Balass, Halderman, Benau, \& Perfetti, 2016; see also Landi \& Perfetti, 2007). Reports such as these strongly suggest 
that accounting for reader characteristics such as decoding ability and word knowledge may not only be important, but necessary, to assess interpretive semantic processes such as complement coercion.

Furthermore, that previous research is based exclusively on the performance of collegiate readers - a population that is comprised of relatively skilled readers - leaves open the possibility that conditions for identifying important variation related to sense selection/inference (i.e., step C) have so far not been met. As mentioned above, poor comprehension is known to be associated with poor use of context and weakness in both inferential processes and in efficient management of competing semantic sense information (Cain \& Oakhill, 1999; Gernsbacher et al., 1990; Long, Oppy, \& Seely, 1999). Because all of a noun's senses are retrieved automatically during initial lexical access, these weaknesses may bear directly on the ability to negotiate coerced expressions. It is also possible that difficulty during sense selection might interact with subsequent type-shifting operations: type-shifting might become costlier under cases of ambiguity, when many event-senses are available - and might be abandoned altogether if sense selection proves too difficult.

The goal of this study was to assess individual differences related to sense selection and type-shifting, and their potential interaction when processing expressions requiring complement coercion. We chose as our starting point the only prior eye tracking investigation of the role played by sense selection during complement coercion (Frisson \& McElree, 2008). We addressed the issue of reader-level variation by measuring individual differences in participants' relative comprehension ability (see Method) to determine whether skill differences co-varied with reading behavior during coercion. In addition, we accounted for the influence of participants' decoding and word knowledge in our analyses, permitting us to draw a clearer 
distinction between semantic weaknesses at the word level and those attributable to higher-level interpretive processes (e.g., Oakhill, 1984; Cain, Oakhill, Barnes, \& Bryant, 2001; Cain \& Oakhill, 1999; cf. Freed, Hamilton, \& Long, 2017; Long et al., 2006). To ensure adequate variability, we recruited a community-based sample of young adults who were not university students. Based on previous work with this population, we expected a broad range in literacyrelated skills across participants (Braze et al., 2007, 2011, 2016; Johns, Matsuki, \& Van Dyke, 2015; Kukona et al., 2016; Kuperman \& Van Dyke, 2011; Li et al., 2019; Magnuson et al., 2011; Shankweiler et al., 2008; Van Dyke et al., 2014), which confers an advantage in our power to detect individual differences (for discussion see Peterson, 2001).

We hypothesize that readers with relatively poor comprehension ability may be slower to resolve complement coercion than good comprehenders. Furthermore, our community-based sample may show differences in processing related to the number of competing event-senses associated with coerced expressions, i.e., a coerced expressions' semantic bias, as operationalized in Frisson \& McElree (2008). Relatively poor comprehenders may experience greater difficulty processing semantically ambiguous coercions than their skilled counterparts, who may process all coerced expressions similarly regardless of the number of possible event-senses. Conversely, if processes associated with sense selection do not determine the coercion cost, then the semantic bias of a coerced expression should not be correlated with any coercion-specific processing difficulty, regardless of comprehension ability. 


\section{INDIVIDUAL DIFFERENCES IN SEMANTIC PROCESSING}

Method

\section{Participants}

97 participants enrolled from the local New Haven, Connecticut, community. We enlisted participants in several ways, including presentations at high schools and adult education centers, advertisements in local newspapers, flyers placed on school campuses, community centers, public transportation hubs, local retail and laundry facilities. All were native English speakers with normal or corrected-to-normal vision and reported no diagnosed language-based learning disability. Participants completed three separate days of testing, including two sessions of behavioral assessment and one experimental session (each lasting no longer than three hours), for which they received $\$ 20 /$ hour as compensation. We obtained informed consent from all participants 18 years of age or older. If a participant was younger than 18, we received informed assent from the participant and consent from a legal guardian. To make our analyses and results comparable to previous research, we excluded 11 participants that were younger than 16 years of age. Of the remaining participants, 12 were missing one or more of the skill assessments used to assess comprehension ability (see below), and so were not included in the final analyses. Thus, we report results for 74 participants (ages 16-24 years, mean 19.5; 35 female). All protocols were approved by the Yale University Human Investigation Committee.

\section{Assessing individual differences}

Relative Comprehension Ability ( $r C A)$. We used a regression-based approach to determining our participants' relative Comprehension Ability (rCA), in which performance on reading comprehension assessments is predicted according to performance on standardized tests of subcomponent skills and abilities, including decoding, word knowledge (i.e., vocabulary), non- 
verbal reasoning, and chronological age. This approach is derived from the Simple View of Reading (Gough \& Tunmer, 1986; Hoover \& Gough, 1990), an influential theoretical framework positing that reading comprehension ability is the product of a reader's decoding skill and oral language comprehension ability. In this context, vocabulary is associated with oral comprehension ability (as reported by numerous large-scale factor analytic studies, e.g., Braze et al., 2016; Protopapas et al., 2013; Tunmer \& Chapman, 2012). Non-verbal reasoning is often a selection criterion in studies of group differences in reading comprehension (e.g., Clarke, Snowling, Truelove, \& Hulme, 2010; Nation, Clarke, Marshall, \& Durand, 2004), and its inclusion accounts for the influence of readers' overall, domain-general cognitive ability on their comprehension ability (for discussion, see Freed et al., 2017; Tiu, Thompson, \& Lewis, 2003). The residuals of the regression reflect the difference between observed and fitted values - that is, the degree by which actual reading comprehension performance deviates from the prediction of the component abilities - so that positive residual values reflect skilled comprehension beyond what component abilities predict, and negative residual values indicative of unexpectedly poor comprehension. Thus, we use the regression's residuals as a continuous index of our participants' relative Comprehension Ability.

Previous research using this technique have related group differences in relative comprehension ability to morphological awareness (MacKay, Levesque, \& Deacon, 2017; Tong, Deacon, \& Cain, 2013; Tong, Deacon, Kirby, Cain, \& Parilla, 2011), syntactic awareness (Tong et al., 2013), capacity for strategic discourse processes and academic outcomes (Kirby, Cain, \& White, 2012; Kwiatkowska, 2012), vocabulary (Li \& Kirby, 2014; Li et al., 2018) and differences in functional connectivity and genetic profiles (Li et al., 2018). This technique also capitalizes on previous assessments of discrepancy-based approaches, which indicate that that 
readers whose comprehension ability is unexpectedly low have similar cognitive profiles to poor readers with poor component abilities, while readers whose comprehension is unexpectedly good have unique cognitive profiles (e.g., Fletcher et al., 1994; Shankweiler et al., 1995; Steubing et al., 2002).

However, use of this approach with small sample sizes may fail to adequately capture readers' cognitive profiles (for discussion see Tong et al., 2011). Therefore, we drew on a larger sample of individuals tested in our lab $(\mathrm{N}=817$, ages $13-24)$ to provide a more robust assessment of the dependencies between variation in reading comprehension and variation in component skills. As noted in other recent studies exploring individual cognitive differences and reading behavior via eye tracking (e.g., Taylor \& Perfetti, 2016), our use of this larger database is likely to more accurately captures the distributional relations between comprehension outcomes and component skills, and permit us to more accurately estimate relative Comprehension Ability in the subset of participants in our study. Thus, although the individuals in the larger sample participated in different experiments over a span of 3-4 years, they all received a common battery of assessments, including standardized measures of both readingrelated component skills and abilities as well as reading comprehension (see below). $78 \%$ of these participants $(n=638)$ both were in the target age range $(16-24)$ and completed all the battery measures required to compute rCA.

\section{Measures of reading and reading-related skills and abilities. All behavioral assessments} were administered during individual, one-on-one sessions. Standardized instruments were chosen to optimize construct validity and test-retest reliability, and are widely used for clinical assessment and diagnosis. Although the test battery contained many assessments, we only 
describe measures that are relevant to this study, i.e., decoding ability, word knowledge (i.e., vocabulary), reading comprehension, and nonverbal cognitive ability.

- Decoding: Assessed using the Woodcock-Johnson-III Tests of Achievement (WJ-III;

Woodcock, McGrew, \& Mather, 2001), Word Attack (reading a list of pseudowords aloud) and Letter-Word Identification (naming words from a list) subtests; and the Test of Word Reading Efficiency (TOWRE; Torgesen, Wagner, \& Rashotte, 1999), Sight Word Efficiency (indexes the number of words that can be named in 45 seconds) and Phonemic Decoding Efficiency (indexes the number of pronounceable nonwords that can be named in 45 seconds) subtests. Across the age range of our participants, the respective average reliability for the WJ-III subtests is .82 and .90 (McGrew \& Woodcock, 2001), and for the TOWRE subtests is .89 and .94 (Torgesen et al., 1999). Because these four assessments measure overlapping aspects of the decoding process, we used them to construct a more reliable composite Decoding variable (as in, e.g., Johns et al., 2018). The construction of the composite is described in the Results.

- Word Knowledge: Peabody Picture Vocabulary Test-Revised (4E, Dunn \& Dunn, 1997), a test of the breadth of receptive vocabulary, in which participants hear a target word and select a picture (from a group of four possibilities) that best depicts its definition. Average reliability is .95 for our age range.

- $\quad$ Reading Comprehension: Assessed using the Woodcock-Johnson-III Tests of Achievement (WJ-3; Woodcock et al., 2001), Passage Comprehension subtest. The task in this test is to silently read printed sentences and paragraphs with critical content words elided from the test materials, and to orally provide the missing words). Average reliability for our age range is .76 (McGrew \& Woodcock, 2001). 
- Nonverbal cognitive ability: Wechsler Abbreviated Scale of Intelligence (Psychological Corp., 1999), Matrix Reasoning subtest, in which participants complete visual inductive reasoning tasks (i.e., choosing from an array of pictures to complete a picture pattern). Average reliability for young adults (age $\geq 17$ ) is .94 (Psychological Corp., 1999).

\section{Materials}

We used the 32 experimental sentence quartets provided in Frisson and McElree (2008). These materials manipulated two factors - SEMANTIC BIAS (strong/weak), and VERB TYPE (coercion/control) - yielding four experimental conditions. SEMANTIC BIAS refers to the ambiguity associated with selecting an event-sense for an entity complement NP (italicized in the examples below) in a coerced expression, with strong bias indicating a strongly preferred eventsense (as in 7), and weak bias indicating no preferred event interpretation among the possible senses (as in 8). For the VERB TYPE manipulation, the coercion verb (first in the bracketed pair) was replaced by a control verb (second in the bracketed pair) corresponding to the most common event-sense interpretation for a given coerced expression.

(7) StRONG BIAS: The teenager [began/read] the novel as soon as he got to his room upstairs.

(8) WEAK BIAS: The waitress [started/served] the coffee as soon as she returned to the counter.

As described in Frisson \& McElree, the length and frequency of the complement NP (the earliest opportunity for the need for coercion to be detected, italicized) in each quartet were matched; in addition, the spillover region following the complement (underlined) was identical across all conditions. We observed that the verbs in the coercing and control conditions differed 
significantly in length: coercing verbs were on average 7.63 characters long, while control verbs averaged 5.5 characters long, $t=28.36, p<.0001$. It is well known that word length affects many aspects of eye movements during reading (e.g., saccade length, fixation point, probability of fixation, etc.; for a review see Rayner, 1998; see also Taylor \& Perfetti, 2016). Therefore, although this was not done in the original study, we accounted for potential effects of length in our analyses.

We created four counterbalanced experimental lists, each containing 120 sentences: 8 practice sentences, 32 experimental sentences, and 80 filler sentences. In the first list, each of our 32 experimental sentence quartets was pseudo-randomly assigned to one of the four conditions strong bias-coercion, strong bias-control, weak bias-coercion, weak bias-control - such that there was an equal number of sentences for each condition. Each quartet's condition assignment in List 1 determined its condition for the remaining lists, such that each item appeared once per list, in a different condition in each. Thus, participants saw all items, but one and only one sentence from each experimental quartet. The filler items in each list were from unrelated experiments, and included sentences with varying levels of morphological, semantic, and syntactic complexity. Following Frisson \& McElree (2008), two-alternative forced choice comprehension questions followed $50 \%$ of the experimental and filler sentences. These were counterbalanced across lists, with the correct responses appearing an equal number of times on the left and right of the screen. An example of a question for our study, related to sentence 8, is "The teenager read ___?", presented with the correct option the novel and the incorrect option the newspaper. 
Eye tracking procedure

An Eyelink 1000 eye tracker (SR Research Ltd., Mississauga, Ontario, Canada) monitored participants' eye movements during sentence reading. Viewing was binocular, and the tracker recorded the movements of the left eye (sampling rate: $1000 \mathrm{~Hz}$ ). Participants were seated $60 \mathrm{~cm}$ from a 19" LCD monitor (1024 x 768 pixels). Prior to the experiment, the experimenter positioned each participant using a chin rest, adjusted for their comfort, to minimize head movement. The eye tracker was then calibrated by having the participant fixate the points in a standard, full-screen nine-point array. Calibration was monitored throughout the experiment according to a between-trials center-left fixation point, and the experimenter recalibrated as necessary. After calibration, all sentences were presented in 14-point Arial font (visual angle/character $=.48^{\circ}$ ) on a single line in the center of the screen.

We instructed the participants to read naturally, and that they would periodically be asked comprehension questions about the sentences they were going to read. Participants began each trial by fixating a calibration point on the center-left of the monitor, where the first letter of the upcoming sentence would appear; when fixation was stable, the experimenter pressed a button to display the trial sentence. After reading each sentence, participants fixated a target in the lower right of the display. Fixating this target elicited one of two routines. If there was no comprehension question associated with the trial, the center-left calibration screen preceding the next trial appeared. If the trial included a comprehension question, it appeared in the center of the screen, along with the two possible answer choices (positioned below the question, in the screen's lower left and right quadrants). Participants responded to the comprehension questions by pressing a button on a keyboard, with the left button indicating the leftmost answer, and the 


\section{INDIVIDUAL DIFFERENCES IN SEMANTIC PROCESSING}

right button indicting the answer on the right. No feedback was provided about response

accuracy. All participants achieved accuracy greater than $90 \%$ for the comprehension questions.

\section{Results}

\section{Assessing individual differences}

\section{Measures of reading and reading related skills and abilities. Descriptive information for} both the larger sample and the subset of participants in our experiment are shown in Table 1, including age and grade equivalents where possible. All analyses are based on raw scores ${ }^{1}$, except for the TOWRE subtests; because some participants completed these timed tests in less than the maximum time allowed, we converted scores on these measures into items-per-minute rates. All analyses, including battery assessments and eye movement data, were analyzed using the R statistical computing environment (version 3.4.4, R Core Team, 2018).

\section{Insert Table 1 About Here}

We created a composite measure of our participants' decoding ability by first standardizing the four relevant individual difference measures (i.e., the WJ-III Word Attack and Letter-Word Identification subtests, and both TOWRE subtests). That is, each was first meancentered (i.e., the mean of each measure is subtracted from its value, setting its mean to zero, but

\footnotetext{
${ }^{1}$ Like many large-scale studies of individual differences in reading and reading-related skills (e.g., Braze et al., 2016), we chose to analyze our participants' raw scores, and to include chronological age as a covariate in our regression analysis of comprehension ability. We adopted this approach for two reasons. First, raw scores are likely to be (slightly) more precise than standardized scores, given that the standardization sample may not be quite equivalent to our community-based sample, which contains a relatively large number of poor readers (Kirby, personal communication). Second, and specifically relevant to our effort to replicate the regression-based approach in our own study, all previous studies using the regression method for calculating comprehension ability have been based on raw, rather than standardized, scores.
} 
INDIVIDUAL DIFFERENCES IN SEMANTIC PROCESSING

leaving the standard deviation unchanged) and then scaled (i.e., the resulting values were converted to z-scores). We then created the Decoding Composite variable by averaging the standardized component measures (all $r \mathrm{~s}>.5$, all $p \mathrm{~s}<.001$ ), and then re-standardizing the resulting values. This approach to creating composite variables has been used in many studies of reading and reading-related skills (e.g., Guo, Roehrig, \& Williams, 2011; Hua \& Keenan, 2014; James et al., 2018; Johns et al., 2018; Sabatini, Sawaki, Shore, \& Scarborough, 2010; StineMorrow, Miller, Gagne, \& Hertzog, 2008; Van Dyke et al., 2014).

Correlations among the resulting set of individual difference measures are shown in Table 2. Following the characterization of correlation strength proposed by Evans (1996), the correlations among the three linguistics variables were all strong $(.60 \geq|r| \leq .79)$, and the correlations between these and the Matrix reasoning measure were either weak $(.20 \geq|r| \leq .39)$ or moderate $(.40 \geq|r| \leq .59)$. Regardless of strength, all correlations were significant (all $p \mathrm{~s}$ $<.0001$, except for the decoding-reasoning correlation in the experimental sample, for which $p$ $=.0032$ ). These correlations are consistent with other studies of language comprehension that have assessed a broad range of individual difference metrics (e.g., Cromley, Snyder-Hogan, \& Luciw-Dubas, 2010; Freed et al., 2017; Long, Prat, Johns, Morris, \& Jonathan, 2008), including previous work from our lab using samples from the same community demographic (e.g., Braze et al., 2007, 2016; Johns et al., 2018; Kukona et al., 2016; Macaruso \& Shankweiler, 2010; Van Dyke et al., 2014). 


\section{INDIVIDUAL DIFFERENCES IN SEMANTIC PROCESSING}

We next used density and quantile-quantile plots to assess univariate normality of all individual difference measures for the total sample. We observed skewness in all measures, which we confirmed using the D'Agostino test for skewness (D'Agostino, 1970; implemented in the moments R package; Komsta \& Novomestky, 2015). If skewness was significant, we applied a Box-Cox power transformation to the raw data (Box \& Cox, 1964). Using the caret $\mathrm{R}$ package (Kuhn, 2016), we calculated optimal lambda $(\lambda)$ exponent values for each measure. For example, a $\lambda$ near zero indicates a natural $\log$ transform, and lambda values close to 1 indicate that no transformation is necessary (i.e., distribution of the transformed data will be identical to the original data), and so on. The procedure assesses a wide range of lambdas for a given variable before settling on an optimal value that will best approximate a normal distribution. After transformation, the resulting values were re-standardized. The details of the D'Agostino tests for skewness, and of the Box-Cox data transformation, appear in Table 3. As the table indicates, no measures exhibited skewness post-transformation.

\section{Insert Table 3 About Here}

Relative Comprehension Ability ( $r C A$ ). We used the regressors listed in Table 3 - participant age, the decoding composite, vocabulary, and nonverbal reasoning - to predict participants' reading comprehension scores. Age did not relate to performance on the reading comprehension measures $(t=1.345, p=.179)$, indicating that there were not developmental differences in this sample of participants. Readers' cognitive abilities did predict comprehension performance, with higher scores associated with greater comprehension performance (decoding composite, $t=$ 
INDIVIDUAL DIFFERENCES IN SEMANTIC PROCESSING

6.681, $p<.0001$; vocabulary, $t=14.748, p<.0001$; nonverbal reasoning, $t=5.338, p<.0001)$.

The predictor variables accounted for $67.35 \%$ of the variance in the outcome measure, which is comparable to previous studies using this method (e.g., Tong et al., 2011). The residuals from this regression analysis were used as a continuous index of relative Comprehension Ability in our analyses of the eye tracking data.

Eye tracking analysis details

Regions and eye movement measures of interest. We analyzed eye tracking data for three regions which have previously been reported in eye tracking studies of complement coercion in English. As in Frisson and McElree (2008), the verb region was the matrix verb, the noun region was comprised of the verb's direct object (i.e., the complement NP) and its preceding determiner, and the spillover region was either the word following the complement NP or, if that word was fewer than five characters in length, the next two words. In previous research, the noun and spillover regions are where coercion-related effects are typically reported. In contrast, the verb region typically does not show coercion-related effects (at least, in early eye tracking measures; later measures may do so, reflecting re-reading after the onset of coercion in subsequent regions). Including this region assesses whether effects related to the coercion conditions in subsequent regions may be attributable to spillover effects from early processing differences between coercion and control conditions at the verb (McElree et al., 2001; Traxler et al., 2002, 2005).

We analyzed four standard measures of eye movement data. First pass time is the sum of all fixations in a region, including both first fixation duration and any subsequent fixations, prior to leaving the region. Regression path duration is the sum of all fixations after a reader fixates a region, but before fixating a succeeding region (i.e., before progressing through the sentence by 
INDIVIDUAL DIFFERENCES IN SEMANTIC PROCESSING

moving the eyes to the right). This measure thus includes time associated with any re-fixations of both the region of interest and previous regions (i.e., because the reader has moved the eyes to the left to re-read previous material). Second pass time is the sum of all fixations after leaving a region to fixate either a previous or subsequent region, usually interpreted as rereading time. Total time is the sum of all fixations in a region. First pass time is widely considered a measure of earlier stages of processing, and both second pass and total time capture relatively later processes. Regression path duration has been characterized as reflecting both early and late processing: early, because any leftward regression is likely triggered by processing difficulty during the initial fixation (or set of fixations) on a region, and late because the time spent rereading may encompass subsequent operations that mitigate the earlier difficulty (Clifton, Staub, \& Rayner, 2007) including, as argued by Traxler and others, coercion (e.g., Traxler et al., 2002, 2005; see also Frisson \& McElree, 2008; McElree et al., 2001, 2006; Pickering et al., 2005).

Three of these measures were reported in Frisson \& McElree (2008): first pass time, second pass time, and total time. These measures are spatially contiguous, i.e., derived from the same scoring region of the sentence. We additionally report analyses of regression path duration, a temporally contiguous measure (i.e., derived from fixations in relation to each other in time, without being in the same scoring region), for two reasons. First, coercion effects have been observed in this measure in previous studies (e.g., Katsika et al., 2012; Traxler et al., 2002, 2005; cf. Delogu et al., 2017); and second, the combination of spatial and temporal measures is essential to understanding the time course of the effect of linguistic variables on readers' eye movements during reading (Liversedge, Paterson, \& Pickering, 1998). 


\section{INDIVIDUAL DIFFERENCES IN SEMANTIC PROCESSING}

Statistical modeling. We used linear mixed-effect regression (LMER; Baayen, 2004, 2008; Baayen et al., 2008 Pinheiro \& Bates, 2000) to analyze the eye tracking data via the lme4 package (Bates, Maechler, Bolker, \& Walker, 2015). All eye tracking analyses used difference coding, such that strong SEMANTIC BIAS (coded as .5) contrasted with weak (coded as -.5), and VERB TYPE control (coded as .5) contrasted with coercion (coded as -.5). In order to account for reader characteristics that might affect earlier stages of processing during coercion, all models included two additional cognitive variables: decoding and word knowledge. In addition, all analyses also included a variable for the length of the scoring regions in each model ${ }^{2}$. Thus, all models included fixed effects (and interactions) of SEMANTIC BIAS, VERB TYPE, and RELATIVE COMPREHENSION ABILITY, with DeCODING SkIll, VocABUlary, and LENGTH included as nuisance covariates of no interest. Although the individual differences regressors were normally distributed over the whole population of participants (see above), these were re-standardized for the eye tracking analysis. Thus, for RELATIVE COMPREHENSION ABILITY, DECODING SKILL, and VOCABULARY, the zero point corresponds to the mean of the subset of readers in the experiment (for a similar approach see Taylor \& Perfetti, 2016). The LENGTH covariate was also meancentered. For all analyses we report the associated $\mathrm{F}$ and $p$-values associated with main effects and interactions of the fixed effects (calculated using Satterthwaite's approximation via the lmerTest package; Kuznetsova et al., 2017), and the $t$-values associated with pairwise

\footnotetext{
${ }^{2}$ An alternative method of modeling length effects that is often adopted is to analyze residual reading times. That is, the number of characters in each scoring region is used to predict reading time in a regression analysis, and then the residuals are extracted and analyzed (e.g., Ferriera \& Clifton, 1986; Rayner, 1998; Trueswell, Tanenhaus, \& Garnsey, 1994). It is more straightforward (and arguably more appropriate; Vasishth, personal communication) to include length as a factor in the analyses, given its established associations with reading time measures in eye tracking studies. Nevertheless, we also analyzed the residualized reading time data and found, as in previous studies of complement coercion (e.g., Traxler et al., 2005), that the pattern of results closely matched that of our analyses based on raw reading time data.
} 
INDIVIDUAL DIFFERENCES IN SEMANTIC PROCESSING

comparisons (calculated using Satterthwaite's approximation via the emmeans package; Lenth, 2018) where appropriate. We do not report effects related to the nuisance covariates.

We determined the appropriate random effects structure for each model via a model selection procedure (Matuschek, Kliegl, Vasishth, Baayen, \& Bates, 2017; see also Bates, Kliegl, Vasishth, \& Baayen, 2015; Seedorff, Oleson, \& McMurray, 2019; Stroup, 2012). We used the RePsychLing package (Baayen, Bates, Kliegl, \& Vasishth, 2015) to determine, for all models, the maximum number of random effects parameters supported by the eye tracking data. Details of the model selection procedure, including the random effects structure used for each model can be found in Appendix A.

Eye movement data preparation. Fixations of less than $80 \mathrm{~ms}$ were deleted, as readers are unable to extract useful information from such brief fixations (Rayner, Pollatsek, Ashby, \& Clifton, 2012; see also Reichle, Rayner, \& Pollatsek, 2003). Following Frisson \& McElree (2008), we set a maximum cutoff for all eye movement measures of 1,600 ms for first pass and second pass time, and 3,000 ms for regression path duration and total time. These minimum and maximum cutoffs deleted less than $1 \%$ of the data.

Our analyses are based on raw reading time data for each measure. We transformed all reading time data in order to satisfy statistical assumptions about their distributional characteristics. We used the the caret package (Kuhn, 2016) to determine the appropriate BoxCox transformation exponent (lambda, $\lambda$ ) for each eye tracking measure (Vasishth, Chen, $\mathrm{Li}, \&$ Guo, 2013; see also Kliegl, Masson, \& Richter, 2010). The $\lambda$ values for each measure in each scoring region appear in Table 4 . As shown in the table, only total time was appropriately log transformed $(\lambda=0)$, as was first pass time in the Noun regions, while other measures were 
reciprocal fourth root ( $\lambda=-.25$; e.g., second pass time in the Verb and Spillover regions) or reciprocal cube root transformed ( $\lambda=-.33$; second pass time in the Noun region). Most approximated one of these three conventional transformations.

Insert Table 4 About Here

Reading time analyses

Verb Region. There were no main effects or interactions in first pass time, regression path duration, or total time in this region. However, we observed a significant SEMANTIC BIAS $\times$ VERB TYPE $\times$ RELATIVE COMPREHENSION ABILITY interaction in second pass time, $\mathrm{F}=5.032, p=.025$, which is depicted in Figure 1. This reflects a significant effect of COMPREHENSION ABILITY in the strongly biased VERB TYPE conditions, $t=-1.984, p=.048$ (Fig. 1, left panel), but not in the weak, $t=-1.146, p=.252$ (Fig. 1, right panel). Follow up contrasts for the strong semantic bias conditions showed that the effect of relative Comprehension Ability was significant in the control sentences, $t=-2.382, p=.018$, but not in coercion sentences, $t<1$. Thus, as our participants' relative comprehension ability increased, they were increasingly likely to re-read strongly-biased control verbs more quickly. In contrast, the reading times for weakly-biased sentences were not influenced by rCA.

Insert Figure 1 About Here 
INDIVIDUAL DIFFERENCES IN SEMANTIC PROCESSING

However, in considering this interaction, the critical effect of interest is not whether rCA was a significant predictor of fixation durations in any single condition, or interacted with VERB TYPE, but whether it was related to the coercion cost, i.e., the difference in processing coercing and non-coercing items. To this end, we estimated the difference between coerced and control conditions in second pass time as a function of rCA by adapting the plot_diff function from the itsadug package (van Rij, Wieling, Baayen, \& van Rijn, 2017; for details about our approach, see Appendix B). As shown in Figure 2, confidence intervals for both strongly and weakly biased sentences overlap with zero, indicating that there is no significant difference between the conditions. Thus, regardless of their relative Comprehension Ability, no reader experienced a coercion cost in this region in second pass time (or, for that matter, in any other measure). Thus, the analyses of the Verb region provide no evidence that coercing verbs are more difficult to process than control verbs. This is an important methodological benchmark, in that that any effects related to coercion in subsequent scoring regions are unlikely to be the result of idiosyncratic processing of the matrix verbs (see also McElree et al., 2001; Traxler et al., 2002, 2005).

Insert Figure 2 About Here

Noun Region. There were no main effects or interactions in first pass time or total time in this region. However, there was a significant effect of COMPREHENSION ABILITY in regression path duration, $\mathrm{F}=4.017, p=.049$. This reflects the overall faster reading times in this region for participants with greater comprehension ability. However, this effect is modulated by a 
significant interaction between SEMANTIC BIAS, VERB TYPE, and RELATIVE COMPREHENSION ABILITY in the same measure, $\mathrm{F}=7.068, p=.008$ (see Figure 3). This is the result of an effect of Relative Comprehension Ability in the strongly biased Verb TyPe conditions, $t=-2.136, p$ $=.033$ (Fig. 3, left panel), but not in the weak, $t=-1.604, p=.109$ (Fig. 3, right panel). Follow up comparisons showed that when semantic bias was strong, there was an effect of rCA in coerced sentences, $t=-2.674, p=.009$, but not in the corresponding control sentences, $t<-1.13$, $p=.261$. Thus, as our participants' comprehension ability increased, they were increasingly likely to read the nouns in strongly-biased coercing sentences more quickly, and as rCA decreased, reading time correspondingly increased. In contrast, the reading times for nouns in weakly-biased sentences were not influenced by rCA. This pattern is different than that observed for the analogous interaction in the previous scoring region: here, increased processing for strongly-biased coercions relative to control sentence is seen as comprehension ability decreases, while the reverse was true for skilled comprehenders.

Insert Figure 3 About Here

Also departing from the pattern observed in the Verb region, this interaction provides evidence that the individual differences in $\mathrm{rCA}$ are related to the coercion cost. As in the previous region, we estimated the difference between coerced and control conditions in regression path duration as a function of $\mathrm{rCA}$, with confidence intervals indicating whether any difference was plausibly non-zero. As depicted in Figure 4, complement NPs were processed differently in coerced and control expressions, for both stronger and weaker comprehenders. This 
INDIVIDUAL DIFFERENCES IN SEMANTIC PROCESSING

pattern differs according to semantic bias. For weakly biased sentences, in which there were many semantic senses from which to select, only relatively skilled readers showed evidence of significantly increased reading time for coercing nouns (Fig 4, right panel); in contrast, as comprehension ability decreased, the coercion cost became negligible. Conversely, when only a single semantic sense was available in the strongly biased sentences, only the weakest comprehenders showed evidence of more costly processing associated with coercing NPs (Fig 4, left panel). All other readers processed complement NPs in strongly biased sentences similarly, regardless of VERB TYPE.

Insert Figure 4 About Here

We observed two additional significant interactions, both in the later second pass reading time measure. First, we found that a SEMANTIC BIAS $\times$ COMPREHENSION ABILITY interaction, $\mathrm{F}=$ 4.298, $p=.039$. This indicates that as comprehension ability increased, time spent re-reading nouns in weakly biased sentences increased, and in strongly biased sentences decreased; the reverse is evident as comprehension ability decreases (Figure 5). Frisson \& McElree (2008) argued such effects of semantic bias were of limited interest, noting that differences between the bias conditions are unrelated to coercion, perhaps reflecting only the relative ease with which a reader might "form a mental model of a teenager reading a novel" relative to "that of a waitress serving coffee" (p. 7). We agree with this reasoning, and therefore we refrain from further interpreting this interaction. 
We also observed a SEMANTIC BIAS $\times$ VERB TYPE interaction in second pass time, $\mathrm{F}=$ $4.165, p=.042$. This interaction is depicted in Figure 6 , and indicates that participants exhibited a coercion cost when semantic bias was weak, $t=2.582, p=.011$, but not when strong semantic bias provided a single interpretation for coerced expressions, $t<1$. No significant differences were evident in the remaining comparisons, i.e., control sentences were processed similarly regardless of semantic bias, $t<1$, as were coerced sentences, $t=-1.885, p=.063$.

\section{Insert Figure 6 About Here}

Spillover Region. There were no main effects in any eye tracking measure, but there were three significant interactions. Two of these were of SEMANTIC BIAS and COMPREHENSION ABILITY, in regression path duration, $\mathrm{F}=5.624, p=.02$, and in total time, $\mathrm{F}=6.027, p=.014$. Both follow the pattern reported for the same interaction described in the Noun region above. As before, we note that these effects are uninformative about coercion-related processes and difficult to interpret on their own theoretical merits, and so again we refrain from further description or comment. The third, in second pass time, was a SEMANTIC BIAS $\times$ VERB TYPE $\times$ COMPREHENSION ABILITY interaction, $\mathrm{F}=3.9, p=.049$. This interaction, shown in Figure 7, is similar to the 3-way interaction observed in regression path duration in the preceding Noun 
INDIVIDUAL DIFFERENCES IN SEMANTIC PROCESSING

region, i.e., rCA has an effect in the strongly biased VERB TYPE conditions, $t=-2.047, p=.042$ (Fig. 7, left panel), but not in the weak, $t<1$ (Fig. 7, right panel). As in the Noun region, when semantic bias was strong, comprehension ability affected reading time for the spillover region in coerced sentences, $t=-2.535, p=.012$, but not for control sentences, $t<1$, such that stronglybiased coerced expressions were read more slowly by poorer comprehenders, and more quickly by skilled comprehenders.

Insert Figure 7 About Here

However, unlike the pattern observed at the critical noun, individual differences in rCA are not associated with a coercion cost in either strongly or weakly biased sentences (Figure 8). Indeed, not only does no reader experience a coercion cost here, it appears that a subset of the more skilled readers process spillover material in the strongly biased control conditions more slowly than the corresponding coerced expressions when re-reading the spillover region (Fig. 8, left panel). This effect, which is considerably removed from readers' initial encounter with the coercing NP, both temporally and spatially, is novel. That is, although coercion-related effects have been observed in later measures in spillover regions (e.g., in total time in Frisson \& McElree, 2008), we know of no study that has reported faster processing of coerced expressions relative to controls. Moreover, it is also apparent that previous studies might not have been able to detect such a pattern of behavior, which relies on a distinction between strong and weak semantic bias (only one previous study does so), and detailed assessment of individual cognitive differences (which no previous work addresses). Finally, that this effect is apparent only in 
readers whose comprehension abilities are stronger than their component abilities might predict confirms the importance of considering this unique cognitive profile in assessing higher-level semantic processing.

Insert Figure 8 About Here

\section{Discussion}

The goal of this study was to test the hypothesis that readers may differ in their ability to negotiate a common form of combinatorial semantic composition - complement coercion - in order to resolve sentences that would otherwise be anomalous. To accomplish this, we conducted an experimental replication, including use of the reported materials, paradigm, and analysis parameters, of Frisson and McElree (2008). Based on previous reports that poor reading comprehension was correlated with an inability to inhibit irrelevant, competing senses of semantically ambiguous words, we tested the possibility that it might also be related to the eventsense selection component (i.e., step C in the formulation proposed by Traxler et al., 2005) of coercion-related processing costs. In order to obtain predictors more directly reflective of higherlevel comprehension processing, we simultaneously modeled our participants' ability in lowerlevel component processes (e.g., decoding and word knowledge) as well as their relative comprehension ability, as predicted by their component skills and abilities.

Our results provide evidence consistent with the hypothesis, first advanced in Frisson \& McElree (2008), that semantic ambiguity - specifically, the frequency and/or number of different interpretations for a verb-noun pairing - may affect the processing of coercing expressions, such 
that "the difference between the weakly preferred-coerced condition and its control would be greater than the difference between the strongly preferred-coerced condition and its control" (p. 6). This Semantic Bias $\times$ Verb TYPE interaction would arise if coercion cost were sensitive to the difficulty of selecting or inferring an interpretation. Supporting this hypothesis, we observed such an interaction in a late, spatial eye tracking measure (second pass time), on the critical complement NP. In addition, by including a temporal eye tracking measure, our individual differences approach revealed two additional, novel findings, both localized to processing of the complement noun. First, the coercion cost was observable during regression path time, earlier than in second pass re-reading. Second, this earlier effect was modulated by our participants' relative comprehension ability. Specifically, even though all readers ultimately showed a coercion cost for weakly biased sentences in second pass re-reading at the complement NP, relatively skilled comprehenders were sensitive to this semantic sense ambiguity earlier than poorer comprehenders. Conversely, even though we found that most of our readers showed no coercion cost for strongly biased sentences in second pass re-reading at the noun (or elsewhere), a subset of readers - those with the lowest relative comprehension ability - do experience an earlier cost for these items, in regression path time. This processing difficulty appears to be more transient than that observed for weak semantic bias, as it neither persists in later measures nor spills over to other scoring regions. Both the eye tracking measures and the location (i.e., the complement NP) in which we observed the coercion cost are consistent with several previous eye tracking studies, even allowing for variability across these earlier reports (e.g., in some studies, the coercion cost appears at the noun, but not in the spillover region, as in Katsika et al., 2012; Traxler et al., 2005; see also Delogu et al., 2017; in the spillover region, but not at the noun, as in Traxler et al., 2002, 2005; and in some combination of verb, noun, and spillover regions, as in 
Lowder \& Gordon, 2016; Traxler et al., 2002, 2005). Our findings suggest that at least some of this empirical inconsistency may be related to individual differences in comprehension ability.

Our results are consistent with prior studies in which coercion-related effects are sensitive to manipulations targeting processes preceding the final type-shifting stage. For example, when Traxler and colleagues (2005) provided context sentences containing inferred information that was relevant to coerced meaning in a target sentence, the coercion cost was eliminated at the Noun region, but manifested in multiple eye tracking measures in the spillover region (experiments 1 and 2); and when the event-structure of the coercion itself was provided in the context sentence, there was no evidence of a coercion cost in the target sentences at all (experiments 3 and 4). Our results are also consistent, in a broad sense, with the main conclusion of Frisson and McElree (2008): that is, both the strongly and weakly biased complement coercion sentences elicit more processing difficulty than their corresponding control sentences. However, because Frisson and McElree did not observe the critical SEMANTIC BIAS $\times$ VERB TYPE interaction, they additionally concluded that sense-selection played no role in the coercion cost, and attributed it entirely to step D type-shifting operations. Our findings are not consistent with this position.

The divergence between our findings and those of Frisson and McElree (2008) could derive from a number of sources. Among the more trivial of these are methodological considerations such as sample size and characteristics of the stimuli. For example, as mentioned above, our sample size nearly doubles that of the original Frisson and McElree study. In addition, we accounted for potential effects related to the length of our scoring regions, which were considered in some previous studies (e.g., Traxler et al., 2005), but not others (e.g., Frisson \& McElree, 2008). More consequentially, the divergence could derive from our modeling of critical 
INDIVIDUAL DIFFERENCES IN SEMANTIC PROCESSING

individual cognitive abilities, both related to early processes that precede operations related to complement coercion, which we believe permits a more precise assessment of potential effects related to "higher-level" interpretive phenomena, and to the online processing of the complement coercion itself.

Further to this point, our results reveal a critical role for individual differences, which is made clear by the comparison of coercion costs in strongly and weakly biased sentences. For weak coercions, where sense selection ability is probed most directly, skilled comprehenders experienced processing difficulty relatively early in processing, with this difficulty persisting during re-reading of the critical NP. In contrast, readers with poorer comprehension ability show the coercion cost for weakly biased sentences only during re-reading. There are at least two potential explanations for this pattern. It could be that poorer comprehenders simply did not notice the need to coerce the complement NP during the initial set of fixations on the complement noun, which is the earliest opportunity for readers to detect the need for coercion. Alternatively, it could be that such comprehenders are simply slower to engage processes related to complement coercion than are more skilled comprehenders. On balance we prefer the latter interpretation, for two reasons. First, if poor comprehenders only detected the need to coerce after fixating the noun and proceeding rightward through the sentence, we might expect some evidence of a coercion cost in the subsequent spillover region - but no reader showed any processing difficulty in this scoring region. Second, this interpretation is consistent with considerable evidence that poorer readers are slower to engage in a variety of higher-level interpretive processes than are skilled readers (e.g., Van Dyke et al., 2014).

Individual differences also inform aspects of the coercion cost associated with strongly biased conditions. Relatively poorer comprehenders show evidence of coercion-related difficulty 
in these conditions earlier than in the weakly-biased conditions, with a cost evident at the complement noun in regression path duration for the former, with the latter emerging (as noted above) only during second pass re-reading. In contrast, more skilled comprehenders seem to negotiate strongly biased coercions without apparent difficulty, regardless of scoring region or eye tracking measure. This pattern is consistent with the hypothesis that readers with lower rCA are relatively slower to engage coercion-related processes such as sense selection, even when the semantic sense of an entity-type NP is unambiguous. That the manifestation of coercion costs is contingent on semantic bias shows that the number of competing event-senses associated with coerced expressions does affect the way readers process such expressions.

Thus, although these results are consistent with one conclusion offered in Frisson and McElree (2008) - that the need to engage in enriched composition will create processing difficulty associated with semantic processes - they bring into question their assertion that complement coercion is "fundamentally different from lexical and semantic ambiguity effects" (p.7). This claim was based on their observation that competing sense information did not interact with the coercion cost. However, our results challenge this conclusion, suggesting that negotiating the ambiguity associated with weakly biased verbs is analogous to relatively greater processing difficulty associated with more ambiguous lexical (e.g., Binder \& Morris, 1995; Duffy, Morris, \& Rayner, 1988), syntactic (e.g., Altmann, Garnham, \& Dennis, 1992; Pickering \& Traxler, 1998) and discourse/referential (e.g., Altmann \& Steedman, 1988; Van Berkum, Koornneef, Otten, \& Nieuwland, 2007; Van Berkum, Brown, \& Hagoort, 1999) information. In each of these areas, as in our study, when contextual information reduces or eliminates ambiguity, processing difficulty is similarly reduced or eliminated. 


\section{INDIVIDUAL DIFFERENCES IN SEMANTIC PROCESSING}

Indeed, our initial hypotheses reflected the idea that it was not just possible, but likely, that there would be individual differences owing to semantic competition among competing event-senses. These were predicated on previous studies showing that skilled readers are able to inhibit competing semantic sense information more efficiently than their less-skilled counterparts, and that poorer readers might be more affected by the ambiguity than more skilled readers. We also suggested that the most skilled readers might be so efficient in negotiating competing interpretations that they might process all coercions similarly - perhaps even showing no evidence of a coercion cost in strongly-biased, semantically unambiguous sentences. Our results support the latter hypothesis, and suggest that processing costs related to complement coercion might be primarily related to the process of sense-selection itself, rather than to operations related to type-shifting and integration. It is clear that relatively skilled readers were more efficient than their less-skilled counterparts, in that they showed evidence of coercionrelated processing for weakly-biased, semantically ambiguous expressions in earlier eye tracking measures, and no costs associated with strongly-biased coercions at all. And although relatively poor comprehenders did show a coercion cost for the strongly-biased items, we do not interpret this as evidence related to the final, type-shifting stage of processing; rather, we view this as indicative of these readers' relatively slower execution of the key comprehension-related processes - an interpretation consistent with, as we note above, much previous research.

This interpretation also highlights what we believe is a key advantage in our study of complement coercion: our assessment of, and ability to account for, our participants' individual cognitive differences in our analyses of their reading behavior. For example, although there is general agreement, on both theoretical and empirical bases, that processing related to decoding ability or semantic mismatch detection is unrelated to complement coercion, no prior study of 
INDIVIDUAL DIFFERENCES IN SEMANTIC PROCESSING

complement coercion directly accounted for this possibility. In addition, by using a continuous measure of relative comprehension ability, we can explore an important question: how do readers whose comprehension ability is poor despite their component abilities behave, and how do readers whose ability exceeds their components of comprehension skill behave? We believe that this question is implicit in many psycholinguistic studies of individual differences with collegiate readers. That is, such studies typically assume that their participants are adequate in their component skills (adequate decoding, or adequate word knowledge, or adequate reasoning ability, or etc.), and wish to examine individual differences that occur in spite of adequacy in these component skills. However, it is not clear that this assumption is warranted: for example, even if some behavior of interest is correlated with, e.g., reading comprehension, omitting the certain influence of related capacities such as, e.g., decoding ability and/or reasoning ability ultimately means that more trivial explanations for observed phenomena remain. By explicitly modeling our participants' component abilities, we increase the likelihood that our findings are attributable to higher-level semantic processes, rather than owing to potential weaknesses deriving from poorer comprehenders' relatively lower decoding ability, or to weaker lexicalsemantic processes (see also Cain \& Oakhill, 1999; Cain, Oakhill, Barnes, \& Bryant, 2001; Oakhill, 1984).

Finally, although we have interpreted our results in the context of the most common linguistic and psycholinguistic accounts of complement coercion - that is, that complement coercion follows the series of processing steps enumerated in the Introduction - we acknowledge that this is not the only theoretical account of complement coercion on offer. To our knowledge, there are two competing accounts, both relatively recent. The first appeals to Surprisal Theory (e.g., Hale, 2001; Levy, 2008), and suggests that coercion-related costs reflect the relative 


\section{INDIVIDUAL DIFFERENCES IN SEMANTIC PROCESSING}

unpredictability of semantically mismatching words, rather than unique operations related to semantic type-shifting (Delogu et al., 2017). The second suggests that only a subset of what are typically considered "coercing verbs" actually elicit processing costs: aspectual verbs, such as begin or start, in contrast to so-called "psychological" coercing verbs, such as enjoy or prefer, which instead elicit pragmatic inferencing processes (Katsika et al., 2012; Lai et al., 2017; Piñango \& Deo, 2016). Under this account, when analyses are restricted to aspectual verbs, processing difficulty specific to the complement noun arises as a function of the need to resolve semantic ambiguity, while processing difficulty at the verb reflects more "exhaustive" retrieval.

We are reluctant to speculate about how our results might be interpreted against these alternative frameworks. Our design was optimized to test predictions related to the "typeshifting" account of complement coercion. Consequently - and perhaps necessarily, since the study we replicated antedates the publication of these theoretical alternatives - the design does not address features that are critical to test predictions related to these accounts. For example, the materials from Frisson \& McElree (2008) do not have sufficient (or balanced) numbers of any of the subsets of coercing verbs identified in the "aspectual" account to support reliable analyses on that basis. Similarly, the absence of a "neutral" condition (i.e., in which the predictability of the complement NP is comparable to coerced expressions, but lower than controls), precludes a direct test of the surprisal account. It is also unclear, for both alternative accounts, how individual cognitive differences might be accommodated - although our findings are arguably consistent with the "aspectual" account, to the extent that it attributes coercion-related difficulty to the need to negotiate semantic ambiguity. Future research should be designed specifically to distinguish among these theoretical accounts. 


\section{Conclusion}

Adult readers are able to adequately encode lexical, structural and semantic relations in sentences that do not require enriched composition, regardless of comprehension skill (Long, Johns, \& Morris, 2006). This is accomplished even when some component processes, including word identification, syntactic parsing, and semantic mismatch detection, are less efficient and/or precise in poor readers (Balass et al., 2016; Bell \& Perfetti, 1994; Johns, et al., 2015; Perfetti, 1985, 1989, 1994, 2007; Perfetti \& Hart, 2002; Perfetti \& Lesgold, 1977). Long and colleagues suggest that the "greatest variation [in component abilities related to reading comprehension] ... is seen in readers' ability to execute high-level interpretive processes" (p. 801). Our study provides the first evidence for a relation between readers' cognitive capabilities and their ability to carry out combinatorial semantic processes online, during the act of reading itself. In addition, although our findings are consistent with research that suggests that readers whose poor comprehension is unexpected relative to their component abilities have semantic difficulties (reviewed in Landi \& Ryherd, 2017), our findings are the first to show that such readers experience difficulty related to "higher-level" interpretive semantic processes, and not just wordlevel semantic difficulty. These results suggest that a comprehensive understanding of coercionrelated phenomena in particular, and complex combinatorial semantic processes in general, must incorporate assessment of individual differences in readers' cognitive skills and abilities. 
INDIVIDUAL DIFFERENCES IN SEMANTIC PROCESSING

\section{Acknowledgements}

This research was supported by the following NIH grants to Haskins Laboratories: P01 HD01994 (PI: Jay G. Rueckl), R01 HD-071988 (PI: David Braze), and R01 HD-065794 (PI:

Kenneth R. Pugh), and R01 HD-073288 (PI: Julie A. Van Dyke). The authors are grateful to Morgan Bontrager, Jenna Duclos, Jonathan Gordils, Nina Gumkowski, Annie Stutzman, and many other research associates at Haskins Laboratories for assistance with data collection; to Kazunaga Matsuki for consultations on initial data analyses; to Ashley G. Lewis and Heidi Sarles-Whittlesey for comments and advice on earlier drafts of this paper; and to P. R. Nelson for support and inspiration. 


\section{INDIVIDUAL DIFFERENCES IN SEMANTIC PROCESSING}

\section{References}

Altmann, G., \& Steedman, M. (1988). Interaction with context during human sentence processing. Cognition, 30(3), 191-238.

Baayen, R. H. (2004). Statistics in psycholinguistics: A critique of some current gold standards. Mental Lexicon Working Papers, 1, Edmonton, 1-45.

Baayen, R. H. (2008). Analyzing linguistic data: A practical introduction to statistics using $R$. New York, NY: Cambridge University Press.

Baayen, R. H., Bates, D., Kliegl, R. \& Vasishth, S. (2015). RePsychLing: Data sets from psychology and linguistics experiments. R package version 0.0.4.

Baayen, R. H., Davidson, D. J., \& Bates, D. M. (2008). Mixed-effects modeling with crossed random effects for subjects and items. Journal of Memory and Language, 59(4), 390-412.

Baggio, G., Choma, T., Van Lambalgen, M., \& Hagoort, P. (2010). Coercion and compositionality. Journal of Cognitive Neuroscience, 22(9), 2131-2140.

Balass, M., Halderman, L. K., Benau, E. M., \& Perfetti, C. A. (2016). Semantic processes and individual differences detected through error-related negativities. Journal of Neurolinguistics, 37, 82-97.

Barr, D. J., Levy, R., Scheepers, C., \& Tily, H. J. (2013). Random effects structure for confirmatory hypothesis testing: Keep it maximal. Journal of Memory and Language, 68(3), 255-278.

Bates, D., Kliegl, R., Vasishth, S., \& Baayen, H. (2015). Parsimonious mixed models. arXiv preprint arXiv:1506.04967.

Bates D., Maechler, M., Bolker, B., \& Walker, S. (2015). Fitting Linear Mixed-Effects Models Using lme4. Journal of Statistical Software, 67(1), 1-48. doi:10.18637/jss.v067.i01. 
INDIVIDUAL DIFFERENCES IN SEMANTIC PROCESSING

Bell, L. C., \& Perfetti, C. A. (1994). Reading skill: Some adult comparisons. Journal of Educational Psychology, 86(2), 244-255.

Box, G. E., \& Cox, D. R. (1964). An analysis of transformations. Journal of the Royal Statistical Society. Series B (Methodological), 211-252.

Braze, D., Katz, L., Magnuson, J. S., Mencl, W. E., Tabor, W., Van Dyke, J. A., Gong, T., Johns, C. L., \& Shankweiler, D. P. (2016). Vocabulary does not complicate the simple view of reading. Reading and Writing, 29(3), 435-451.

Braze, D., Mencl, W. E., Tabor, W., Pugh, K. R., Constable, R. T., Fulbright, R. K., ... \& Shankweiler, D. P. (2011). Unification of sentence processing via ear and eye: an fMRI study. Cortex, 47(4), 416-431.

Braze, D., Tabor, W., Shankweiler, D. P., \& Mencl, W. E. (2007). Speaking up for vocabulary reading skill differences in young adults. Journal of Learning Disabilities, 40(3), 226243.

Cain, K., \& Oakhill, J. V. (1999). Inference making ability and its relation to comprehension failure in young children. Reading and Writing, 11(5-6), 489-503.

Cain, K., Oakhill, J. V., Barnes, M. A., \& Bryant, P. E. (2001). Comprehension skill, inferencemaking ability, and their relation to knowledge. Memory \& Cognition, 29(6), 850-859.

Clarke, P. J., Snowling, M. J., Truelove, E., \& Hulme, C. (2010). Ameliorating children's reading-comprehension difficulties: A randomized controlled trial. Psychological Science, 21(8), 1106-1116.

Cromley, J. G., Snyder-Hogan, L. E., \& Luciw-Dubas, U. A. (2010). Reading comprehension of scientific text: A domain-specific test of the direct and inferential mediation model of reading comprehension. Journal of Educational Psychology, 102(3), 687-700. 
INDIVIDUAL DIFFERENCES IN SEMANTIC PROCESSING

D'Agostino, R. B. (1970). Transformation to normality of the null distribution of g1. Biometrika, 679-681.

Delogu, F., Crocker, M. W., \& Drenhaus, H. (2017). Teasing apart coercion and surprisal: Evidence from eye-movements and ERPs. Cognition, 161, 46-59.

Dunn, L. M., \& Dunn, L. M. (1997). Peabody Picture Vocabulary Test (3rd ed.). American Guidance Services: Circle Pines, MN.

Evans, J. D. (1996). Straightforward statistics for the behavioral sciences. Pacific Grove, CA: Brooks/Cole Publishing Company.

Fletcher, J. M., Shaywitz, S. E., Shankweiler, D. P., Katz, L., Liberman, I. Y., Stuebing, K. K., ... \& Shaywitz, B. A. (1994). Cognitive profiles of reading disability: Comparisons of discrepancy and low achievement definitions. Journal of Educational Psychology, 86(1), 6-23.

Freed, E. M., Hamilton, S. T., \& Long, D. L. (2017). Comprehension in proficient readers: The nature of individual variation. Journal of Memory and Language, 97, 135-153.

Frisson, S., \& McElree, B. (2008). Complement coercion is not modulated by competition: Evidence from eye movements. Journal of Experimental Psychology: Learning, Memory, and Cognition, 34(1), 1-11.

Gernsbacher, M. A., \& Robertson, R. R. (1995). Reading skill and suppression revisited. Psychological Science, 6(3), 165-169.

Gernsbacher, M. A., Varner, K. R., \& Faust, M. E. (1990). Investigating differences in general comprehension skill. Journal of Experimental Psychology: Learning, Memory, and Cognition, 16(3), 430-445. 


\section{INDIVIDUAL DIFFERENCES IN SEMANTIC PROCESSING}

Gough, P. B., \& Tunmer, W. E. (1986). Decoding, reading, and reading disability. Remedial and Special Education, 7(1), 6-10.

Guo, Y., Roehrig, A. D., \& Williams, R. S. (2011). The relation of morphological awareness and syntactic awareness to adults' reading comprehension: Is vocabulary knowledge a mediating variable?. Journal of Literacy Research, 43(2), 159-183.

Hale, J. (2001, June). A probabilistic Earley parser as a psycholinguistic model. In Proceedings of the second meeting of the North American chapter of the Association for Computational Linguistics on language technologies (pp. 1-8). Association for Computational Linguistics.

Heyselaar, E., Peeters, D., \& Hagoort, P. (2018). Do we predict upcoming speech content in naturalistic environments? BioRxiv. https://doi.org/10.1101/366427

Hoover, W. A., \& Gough, P. B. (1990). The simple view of reading. Reading and Writing, 2(2), $127-160$.

Hua, A. N., \& Keenan, J. M. (2014). The role of text memory in inferencing and in comprehension deficits. Scientific Studies of Reading, 18(6), 415-431.

Husband, E. M., Kelly, L. A., \& Zhu, D. C. (2011). Using complement coercion to understand the neural basis of semantic composition: evidence from an fMRI study. Journal of Cognitive Neuroscience, 23(11), 3254-3266.

Jackendoff, R. (1997). The architecture of the language faculty. Cambridge, MA: MIT Press. Jackendoff, R. (2002). Foundations of language. New York, NY: Oxford University Press.

James, A. N., Fraundorf, S. H., Lee, E. K., \& Watson, D. G. (2018). Individual differences in syntactic processing: Is there evidence for reader-text interactions?. Journal of Memory and Language, 102, 155-181. 
Johns, C. L., Jahn, A. A., Jones, H. R., Kush, D., Molfese, P. J., Van Dyke, J. A., ... \& Braze, D. (2018). Individual differences in decoding skill, print exposure, and cortical structure in young adults. Language, Cognition and Neuroscience, 1-21.

Johns, C. L., Matsuki, K., \& Van Dyke, J. A. (2015). Poor readers' retrieval mechanism: efficient access is not dependent on reading skill. Frontiers in Psychology, 6: 1552.

Katsika, A., Braze, D., Deo, A., \& Piñango, M. M. (2012). Complement coercion: Distinguishing between type-shifting and pragmatic inferencing. The Mental Lexicon, 7(1), 58-76.

Keenan, J. M., Hua, A. N., Meenan, C. E., Pennington, B. F., Willcutt, E., \& Olson, R. K. (2014). Issues in identifying poor comprehenders. L'Année psychologique, 114(4), 753777.

Keenan, J. M., \& Meenan, C. E. (2014). Test differences in diagnosing reading comprehension deficits. Journal of Learning Disabilities, 47(2), 125-135.

King, J., \& Just, M. A. (1991). Individual differences in syntactic processing: The role of working memory. Journal of Memory and Language, 30(5), 580-602.

Kirby, J. R., Cain, K., \& White, B. (2012). Deeper learning in reading comprehension. In J. R. Kirby \& M. J. Lawson (Eds.), Enhancing the quality of learning: Dispositions, instruction, and learning processes (pp. 315-338). New York, NY: Cambridge University Press.

Kliegl, R., Masson, M. E., \& Richter, E. M. (2010). A linear mixed model analysis of masked repetition priming. Visual Cognition, 18(5), 655-681.

Komsta, L. \& Novomestky, F. (2015). moments: Moments, cumulants, skewness, kurtosis and related tests. R package version 0.14. https:/CRAN.R-project.org/package=moments 
Kukona, A, Braze, D., Johns, C. L., Mencl, W. E., Van Dyke, J. A., Magnuson, J. S., Pugh, K. R., Shankweiler, D. P., \& Tabor, W. (2016). The real-time prediction and inhibition of linguistic outcomes: Effects of language and literacy skill. Acta Psychologia, 171, 72-84.

Kuhn, M. (2016). caret: Classification and regression training. R package version 6.0-71. URL https://CRAN.R-project.org/package=caret.

Kuperberg, G. R., Choi, A., Cohn, N., Paczynski, M., \& Jackendoff, R. (2010).

Electrophysiological correlates of complement coercion. Journal of Cognitive Neuroscience, 22(12), 2685-2701.

Kuznetsova, A., Brockhoff, P. B., \& Christensen, R. H. B. (2015). lmerTest package: Tests in linear mixed effects models. Journal of Statistical Software, 82(13), 1-26. doi: 10.18637/jss.v082.i13.

Kwiatkowska-White, B. (2012). Understanding reading comprehension performance in high school students. Unpublished doctoral dissertation, Queen's University, Kingston.

Lai, Y. Y., Lacadie, C., Constable, T., Deo, A., \& Piñango, M. M. (2017). Complement coercion as the processing of aspectual verbs: evidence from self-paced reading and fMRI. In Compositionality and concepts in linguistics and psychology (pp. 191-222). Springer.

Landi, N., \& Perfetti, C. A. (2007). An electrophysiological investigation of semantic and phonological processing in skilled and less-skilled comprehenders. Brain and Language, $102(1), 30-45$.

Landi, N., \& Ryherd, K. (2017). Understanding specific reading comprehension deficit: A review. Language and Linguistics Compass, 11(2), e12234.

Lauwers, P., \& Willems, D. (2011). Coercion: Definition and challenges, current approaches, and new trends. Linguistics, 49(6), 1219-1235. 
Lenth, R. (2018). emmeans: Estimated marginal means, aka least-squares means. R package version 1.2.3. URL https://CRAN.R-project.org/package=means

Levy, R. (2008). Expectation-based syntactic comprehension. Cognition, 106(3), 1126-1177.

Li, M., Braze, D., Kukona, A., Johns, C. L., Tabor, W., Van Dyke, J. A., Mencl, W. E., Shankweiler, D. P., Pugh, K. R., \& Magnuson, J. S. (2019). Individual differences in subphonemic sensitivity and reading-related abilities. Manuscript under review. Available from PsyArXiv, http://doi.org/10.17605/OSF.IO/3FNCY

Li, M., \& Kirby, J. R. (2014). Unexpected poor comprehenders among adolescent ESL students. Scientific Studies of Reading, 18(2), 75-93.

Li, M., Malins, J. G., DeMille, M. M., Lovett, M. W., Truong, D. T., Epstein, K., ... \& Frijters, J. C. (2018). A molecular-genetic and imaging-genetic approach to specific comprehension difficulties in children. NPJ Science of Learning, 3(1), 20.

Liversedge, S. P., Paterson, K. B., \& Pickering, M. J. (1998). Eye movements and measures of reading time. In Eye guidance in reading and scene perception (pp. 55-75). Oxford: Elsevier Science.

Long, D. L., Johns, C. L., \& Morris, P. E. (2006). Comprehension ability in mature readers. In M. Traxler \& M. Gernsbacher (Eds.), Handbook of psycholinguistics, $2^{\text {nd }}$ ed. (pp. 801833). Burlington, MA: Academic Press.

Long, D. L., Seely, M. R., \& Oppy, B. J. (1999). The strategic nature of less skilled readers' suppression problems. Discourse Processes, 27(3), 281-302.

Long, D. L., \& Prat, C. S. (2008). Individual differences in syntactic ambiguity resolution: Readers vary in their use of plausibility information. Memory \& Cognition, 36(2), 375391. 


\section{INDIVIDUAL DIFFERENCES IN SEMANTIC PROCESSING}

Long, D. L., Prat, C., Johns, C., Morris, P., \& Jonathan, E. (2008). The importance of knowledge in vivid text memory: An individual-differences investigation of recollection and familiarity. Psychonomic Bulletin \& Review, 15(3), 604-609.

Lowder, M. W., \& Gordon, P. C. (2015). The manuscript that we finished: Structural separation reduces the cost of complement coercion. Journal of Experimental Psychology: Learning, Memory, and Cognition, 41(2), 526-540.

Lowder, M. W., \& Gordon, P. C. (2016). Eye-tracking and corpus-based analyses of syntaxsemantics interactions in complement coercion. Language, Cognition and Neuroscience, 31(7), 921-939.

Macaruso, P., \& Shankweiler, D. (2010). Expanding the simple view of reading in accounting for reading skills in community college students. Reading Psychology, 31(5), 454-471.

MacCallum, R. C., Zhang, S., Preacher, K. J., \& Rucker, D. D. (2002). On the practice of dichotomization of quantitative variables. Psychological Methods, 7(1), 19.

MacDonald, M. C., \& Christiansen, M. H. (2002). Reassessing working memory: Comment on Just and Carpenter (1992) and Waters and Caplan (1996). Psychological Review, 109(1), $35-54$.

MacKay, E. J., Levesque, K., \& Deacon, S. H. (2017). Unexpected poor comprehenders: An investigation of multiple aspects of morphological awareness. Journal of Research in Reading, 40(2), 125-138.

Magnuson, J., Kukona, A., Braze, D., Johns, C.L., Van Dyke, J.A., Tabor, W., Mencl, W.E., \& Shankweiler, D. (2011). Phonological instability in young adult poor readers: Time course measures and computational modeling. In P. McCardle, B. Miller, J.R. Lee, \& 


\section{INDIVIDUAL DIFFERENCES IN SEMANTIC PROCESSING}

O.J.L. Tzeng (Eds.), Dyslexia across languages (pp. 184-201). Baltimore, MD: Paul H. Brookes Publishing Co.

Matuschek, H., Kliegl, R., Vasishth, S., Baayen, H., \& Bates, D. (2017). Balancing Type I error and power in linear mixed models. Journal of Memory and Language, 94, 305-315.

McElree, B., Pylkkänen, L., Pickering, M. J., \& Traxler, M. J. (2006). A time course analysis of enriched composition. Psychonomic Bulletin \& Review, 13(1), 53-59.

McElree, B., Traxler, M. J., Pickering, M. J., Seely, R. E., \& Jackendoff, R. (2001). Reading time evidence for enriched composition. Cognition, 78(1), B17-B25.

McGrew, K. S., \& Woodcock, R. W. (2001). Technical manual: Woodcock-Johnson III. Itasca, IL: Riverside.

Moens, M., \& Steedman, M. (1988). Temporal ontology and temporal reference. Computational Linguistics, 14(2), 15-28.

Nation, K., Clarke, P., Marshall, C. M., \& Durand, M. (2004). Hidden language impairments in children: Parallels between poor reading comprehension and specific language impairment?. Journal of Speech, Language, and Hearing Research, 47(1), 199-211.

Nation, K., \& Snowling, M. J. (1998). Individual differences in contextual facilitation: Evidence from dyslexia and poor reading comprehension. Child development, 69(4), 996-1011.

Oakhill, J. (1984). Inferential and memory skills in children's comprehension of stories. British Journal of Educational Psychology, 54(1), 31-39.

Osborne, J. W. (2010). Improving your data transformations: Applying the Box-Cox transformation. Practical Assessment, Research \& Evaluation, 15(12), 1-9. 


\section{INDIVIDUAL DIFFERENCES IN SEMANTIC PROCESSING}

Pearlmutter, N. J., \& MacDonald, M. C. (1995). Individual differences and probabilistic constraints in syntactic ambiguity resolution. Journal of Memory and Language, 34(4), $521-542$

Pelletier, F. J. (1994). The principle of semantic compositionality. Topoi, 13(1), 11-24.

Perfetti, C. A. (1985). Reading ability. Oxford University Press.

Perfetti, C. A. (1989). There are generalized abilities and one of them is reading. Knowing, learning, and instruction: Essays in honor of Robert Glaser (pp. 307-335). Hillsdale, NJ: Erlbaum.

Perfetti, C. A. (1994). Psycholinguistics and reading ability. In M. A. Gernsbacher (Ed.), Handbook of psycholinguistics (pp. 849-894). San Diego, CA, US: Academic Press.

Perfetti, C. (2007). Reading ability: Lexical quality to comprehension. Scientific Studies of Reading, 11(4), 357-383.

Peterson, R. A. (2001). On the use of college students in social science research: Insights from a second-order meta-analysis. Journal of Consumer Research, 28, 450-461.

Perfetti, C. A., \& Hart, L. (2001). The lexical basis of comprehension skill. In D. S. Gorfein (Ed.), Decade of behavior. On the consequences of meaning selection: Perspectives on resolving lexical ambiguity (pp. 67-86). Washington, D.C.: American Psychological Association.

Perfetti, C. A., \& Hart, L. (2002). The lexical quality hypothesis. Precursors of functional literacy, 11, 67-86.

Perfetti, C. A., \& Lesgold, A. M. (1977). Discourse comprehension and sources of individual differences. In P. A. Carpenter \& M. A. Just (Eds). Cognitive processing in comprehension (pp. 141-183). Hillsdale, NJ: Erlbaum. 


\section{INDIVIDUAL DIFFERENCES IN SEMANTIC PROCESSING}

Pickering, M. J., McElree, B., \& Traxler, M. J. (2005). The difficulty of coercion: A response to de Almeida. Brain and Language, 93(1), 1-9.

Pickering, M. J., \& Traxler, M. J. (1998). Plausibility and recovery from garden paths: An eyetracking study. Journal of Experimental Psychology: Learning, Memory, and Cognition, 24(4), 940-961.

Piñango, M. M., \& Deo, A. (2016). Reanalyzing the complement coercion effect through a generalized lexical semantics for aspectual verbs. Journal of Semantics, 33(2), 359-408.

Piñango, M. M., \& Zurif, E. B. (2001). Semantic operations in aphasic comprehension:

Implications for the cortical organization of language. Brain and Language, 79(2), 297308.

Piñango, M. M., Zurif, E., \& Jackendoff, R. (1999). Real-time processing implications of enriched composition at the syntax-semantics interface. Journal of Psycholinguistic Research, 28(4), 395-414.

Preacher, K. J., Rucker, D. D., MacCallum, R. C., \& Nicewander, W. A. (2005). Use of the extreme groups approach: a critical reexamination and new recommendations. Psychological Methods, 10(2), 178-192.

Protopapas, A., Mouzaki, A., Sideridis, G. D., Kotsolakou, A., \& Simos, P. G. (2013). The role of vocabulary in the context of the simple view of reading. Reading \& Writing Quarterly, $29(2), 168-202$

Psychological Corp. (1999). WASI: Wechsler Abbreviated Scale of Intelligence. San Antonio, TX.

Pustejovsky, J. (1991). The syntax of event structure. Cognition, 41(1-3), 47-81.

Pustejovsky, J. (1995). The generative lexicon. Cambridge, MA: MIT Press. 
Pustejovsky, J. (2011). Coercion in a general theory of argument selection. Linguistics, 49(6), 1401-1431.

Pylkkänen, L. (2008). Mismatching meanings in brain and behavior. Language and Linguistics Compass, 2(4), 712-738.

Pylkkänen, L., \& McElree, B. (2006). The syntax-semantics interface: On-line composition of sentence meaning. . In M. Traxler \& M. Gernsbacher (Eds.), Handbook of psycholinguistics, $2^{\text {nd }}$ ed. (pp. 539-579). Burlington, MA: Academic Press.

Pylkkänen, L., \& McElree, B. (2007). An MEG study of silent meaning. Journal of Cognitive Neuroscience, 19(11), 1905-1921.

R Core Team (2018). R: A language and environment for statistical computing. R Foundation for Statistical Computing, Vienna, Austria. URL https://www.R-project.org/.

Rayner, K. (1998). Eye movements in reading and information processing: 20 years of research. Psychological Bulletin, 124(3), 372-422.

Rayner, K., Pollatsek, A., Ashby, J., \& Clifton Jr, C. (2012). Psychology of reading (2E). New York, NY: Psychology Press.

Reichle, E. D., Rayner, K., \& Pollatsek, A. (2003). The EZ Reader model of eye-movement control in reading: Comparisons to other models. Behavioral and brain sciences, 26(4), 445-476.

Sabatini, J. P., Sawaki, Y., Shore, J. R., \& Scarborough, H. S. (2010). Relationships among reading skills of adults with low literacy. Journal of Learning Disabilities, 43(2), 122138.

Schumacher, P. B. (2013). When combinatorial processing results in reconceptualization: toward a new approach of compositionality. Frontiers in Psychology, 4, 677. 


\section{INDIVIDUAL DIFFERENCES IN SEMANTIC PROCESSING}

Seedorff, M., Oleson, J., \& McMurray, B. (2019). Maybe maximal: Good enough mixed models optimize power while controlling Type I error. Manuscript under review. Available from PsyArXiv https://doi.org/10.31234/osf.io/xmhfr

Shankweiler, D. (1989). How problems of comprehension are related to difficulties in word reading. In D. Shankweiler \& I.Y. Liberman (Eds.), Phonology and reading disability: Solving the reading puzzle (pp. 35-68). Ann Arbor: University of Michigan Press.

Shankweiler, D., Crain, S., Katz, L., Fowler, A. E., Liberman, A. M., Brady, S. A., ... \& Stuebing, K. K. (1995). Cognitive profiles of reading-disabled children: Comparison of language skills in phonology, morphology, and syntax. Psychological Science, 6(3), 149156.

Shankweiler, D., Lundquist, E., Katz, L., Stuebing, K. K., Fletcher, J. M., Brady, S., ... \& Shaywitz, B. A. (1999). Comprehension and decoding: Patterns of association in children with reading difficulties. Scientific Studies of Reading, 3(1), 69-94.

Stanovich, K. E. (1982). Individual differences in the cognitive processes of reading: I. Word decoding. Journal of Learning Disabilities, 15(8), 485-493.

Stroup, W. W. (2012). Generalized linear mixed models: Modern concepts, methods and applications. Boca Raton, FL: CRC Press.

Stuebing, K. K., Fletcher, J. M., LeDoux, J. M., Lyon, G. R., Shaywitz, S. E., \& Shaywitz, B. A. (2002). Validity of IQ-discrepancy classifications of reading disabilities: A metaanalysis. American Educational Research Journal, 39(2), 469-518.

Stine-Morrow, E. A., Soederberg Miller, L. M., Gagne, D. D., \& Hertzog, C. (2008). Selfregulated reading in adulthood. Psychology and Aging, 23(1), 131-153. 


\section{INDIVIDUAL DIFFERENCES IN SEMANTIC PROCESSING}

Taylor, J. N., \& Perfetti, C. A. (2016). Eye movements reveal readers' lexical quality and reading experience. Reading and Writing, 29(6), 1069-1103.

Tiu Jr, R. D., Thompson, L. A., \& Lewis, B. A. (2003). The role of IQ in a component model of reading. Journal of Learning Disabilities, 36(5), 424-436.

Tong, X., Deacon, S. H., \& Cain, K. (2014). Morphological and syntactic awareness in poor comprehenders: Another piece of the puzzle. Journal of Learning Disabilities, 47(1), 2233.

Tong, X., Deacon, S. H., Kirby, J. R., Cain, K., \& Parrila, R. (2011). Morphological awareness: A key to understanding poor reading comprehension in English. Journal of Educational Psychology, 103(3), 523-534.

Torgesen, J. K., Wagner, R. K. and Rashotte, C. A. (1999). Test of word reading efficiency. Austin, TX: Pro-Ed.

Traxler, M. J., McElree, B., Williams, R. S., \& Pickering, M. J. (2005). Context effects in coercion: Evidence from eye movements. Journal of Memory and Language, 53(1), 1-25.

Traxler, M. J., Pickering, M. J., \& McElree, B. (2002). Coercion in sentence processing: Evidence from eye-movements and self-paced reading. Journal of Memory and Language, 47(4), 530-547.

Tunmer, W. E., \& Chapman, J. W. (2012). The simple view of reading redux: Vocabulary knowledge and the independent components hypothesis. Journal of Learning Disabilities, $45(5), 453-466$.

Van Dyke, J. A., Johns, C. L., \& Kukona, A. (2014). Low working memory capacity is only spuriously related to poor reading comprehension. Cognition, 131(3), 373-403. 
van Rij J, Wieling M, Baayen R and van Rijn H (2017). itsadug: Interpreting Time Series and Autocorrelated Data Using GAMMs. R package version 2.3.

Vasishth, S., Chen, Z., Li, Q., \& Guo, G. (2013). Processing Chinese relative clauses: Evidence for the subject-relative advantage. PloS one, 8(10), e77006.

Wagner, R. K., Piasta, S. B., \& Torgesen, J. K. (2006). Learning to read. In M. Traxler \& M. Gernsbacher (Eds.), Handbook of psycholinguistics, $2^{\text {nd }}$ ed. (pp. 1111-1142), Burlington, MA: Academic Press.

Wieling, M. (2018). Analyzing dynamic phonetic data using generalized additive mixed modeling: A tutorial focusing on articulatory differences between L1 and L2 speakers of English. Journal of Phonetics, 70, 86-116. https://doi.org/10.1016/j.wocn.2018.03.002

Wood, S. N. (2011). Fast stable restricted maximum likelihood and marginal likelihood estimation of semiparametric generalized linear models. Journal of the Royal Statistical Society. Series B (Statistical Methodology), 73(1), 3-36.

Woodcock, R. W., McGrew, K. S., \& Mather, N. (2001). Woodcock-Johnson III Tests of Achievement. Itasca, IL: Riverside.

Zarcone, A., McRae, K., Lenci, A., \& Padó, S. (2017). Complement coercion: The joint effects of type and typicality. Frontiers in Psychology, 8, 1987. 


\section{INDIVIDUAL DIFFERENCES IN SEMANTIC PROCESSING}

Full Sample $(N=638) \quad$ Experimental Sample $(n=74)$

\begin{tabular}{|c|c|c|c|c|c|c|c|c|c|c|}
\hline Measure & Max. & & Ran & & $M$ & $S D$ & & Range & $M$ & $S D$ \\
\hline 1. Word identification & 76 & 35 & - & 76 & 67.40 & 6.20 & 45 & -76 & 68.59 & 5.37 \\
\hline Grade equivalent & $>18$ & 3.5 & - & 19 & 13.49 & 4.04 & 7.1 & -19 & 12.79 & 3.72 \\
\hline 2. Word attack & 32 & 9 & - & 32 & 27.36 & 4.15 & 9 & -32 & 28.80 & 3.38 \\
\hline Grade equivalent & $>18$ & 2.1 & - & 19 & 12.65 & 4.72 & 4.2 & -19 & 13.18 & 4.42 \\
\hline 3. Sight word efficiency & 104 & 25 & - & 104 & 87.46 & 12.32 & 54 & -104 & 91.08 & 11.30 \\
\hline Grade equivalent & $>12.6$ & 1.6 & - & 13 & 9.63 & 2.67 & 3.4 & -13 & 10.39 & 2.37 \\
\hline Rate (items/min.) & $n / a$ & 57 & - & 190 & 118.21 & 18.67 & 72 & -190 & 125.52 & 20.72 \\
\hline 4. Phonemic decoding & 63 & 10 & - & 63 & 48.11 & 11.77 & 10 & -63 & 52.61 & 9.33 \\
\hline Grade equivalent & $>12.6$ & 1 & - & 13 & 9.32 & 3.26 & 1.8 & -13 & 10.51 & 2.68 \\
\hline Rate (items/min.) & $n / a$ & 13 & - & 125 & 65.87 & 18.29 & 13 & -118 & 73.06 & 16.71 \\
\hline 5. Vocabulary knowledge & 204 & 85 & - & 228 & 195.91 & 19.60 & 165 & -222 & 198.85 & 14.26 \\
\hline Age equivalent & $>24.9$ & 5.3 & - & 25 & 19.60 & 5.35 & 11.7 & -25 & 20.20 & 4.71 \\
\hline 6. Matrix reasoning & 48 & 9 & - & 29 & 20.29 & 4.19 & 9 & -28 & 20.76 & 3.95 \\
\hline 7. Reading comprehension & 47 & 20 & - & 47 & 37.13 & 4.58 & 29 & -46 & 37.42 & 4.01 \\
\hline Grade equivalent & $>18$ & 2.7 & - & 19 & 12.65 & 4.72 & 3.8 & -19 & 12.01 & 4.93 \\
\hline
\end{tabular}

Note: Grade equivalent scores for some measures include non-numerical values. For example, "> 12", corresponds to a grade equivalent greater than grade 12 and 6th months. In order to enable numerical summaries of grade equivalent scores, we convert these to the next highest integer, e.g., "> 12 " becomes 13, "> 18" becomes 19, and" > 24.92" becomes 25. However, all analyses are based on raw scores.

Table 1. Descriptive statistics for all battery measures. 
INDIVIDUAL DIFFERENCES IN SEMANTIC PROCESSING

\begin{tabular}{llcccc}
\hline Measure & $\mathbf{1}$ & $\mathbf{2}$ & $\mathbf{3}$ & $\mathbf{4}$ \\
\hline & & & & & \\
1. Decoding composite & - & .7310 & .6983 & .3388 \\
2. Vocabulary knowledge & .6814 & - & .7861 & .4458 \\
3. Reading comprehension & .6891 & .7585 & - & .4502 \\
4. Matrix reasoning & .5527 & .5963 & .5928 & - \\
\hline
\end{tabular}

Note: Correlations for the full sample appear below the diagonal, and for the experimental sample above the diagonal.

Table 2. Pearson's correlations ( $r$ ) among the individual differences regressors. 
INDIVIDUAL DIFFERENCES IN SEMANTIC PROCESSING

\begin{tabular}{llcrr}
\hline & Measure & Skew & $\boldsymbol{\lambda}$ & Box-Cox Skew \\
\hline & & & & \\
1. & Participant age & 0.1192 & $\mathrm{n} / \mathrm{a}$ & $\mathrm{n} / \mathrm{a}$ \\
2. Decoding composite & $-0.8444^{* *}$ & 1.46 & -0.0042 \\
3. & Vocabulary knowledge & $-1.1155^{* *}$ & 4.53 & -0.1412 \\
4. Reading comprehension & $-0.2477^{*}$ & 1.76 & -0.0458 \\
5. Matrix reasoning & $-0.7791 * *$ & 2.14 & -0.0959 \\
& & & \\
\hline$* p<.05 \quad * * p<.0001$ & & &
\end{tabular}

Table 3. Results of the D'Agostino test for skewness before and after Box-Cox transformation, and associated lambda $(\lambda)$ values. 
INDIVIDUAL DIFFERENCES IN SEMANTIC PROCESSING

\begin{tabular}{lcrr}
\hline \multicolumn{1}{c}{ Measure } & Verb & Noun & Spillover \\
\hline & & & \\
First pass time & -.1836 & .0172 & -.1024 \\
Regression path duration & -.3697 & -.1230 & -.3028 \\
Second pass time & -.2564 & -.3349 & -.2226 \\
Total time & -.0486 & .0599 & -.0005 \\
& & & \\
\hline
\end{tabular}

Table 4. Lambda $(\lambda)$ values for all eye movement measures in each scoring region. 


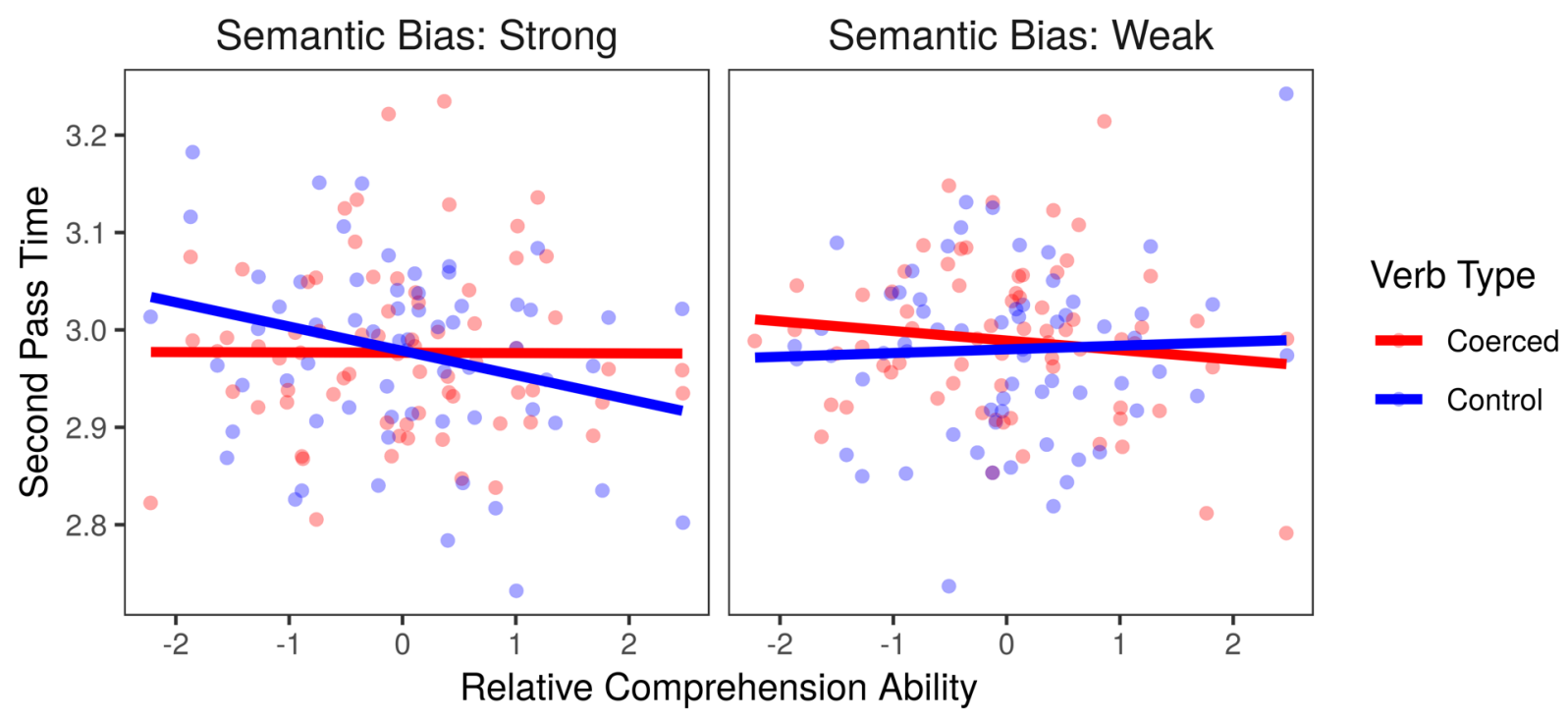

Figure 1. The interaction of COMPREhENSION ABILITy, Verb TyPe, and SEMANTIC BIAS in second pass time at the VERB. Reading times are reciprocal fourth root transformed. 


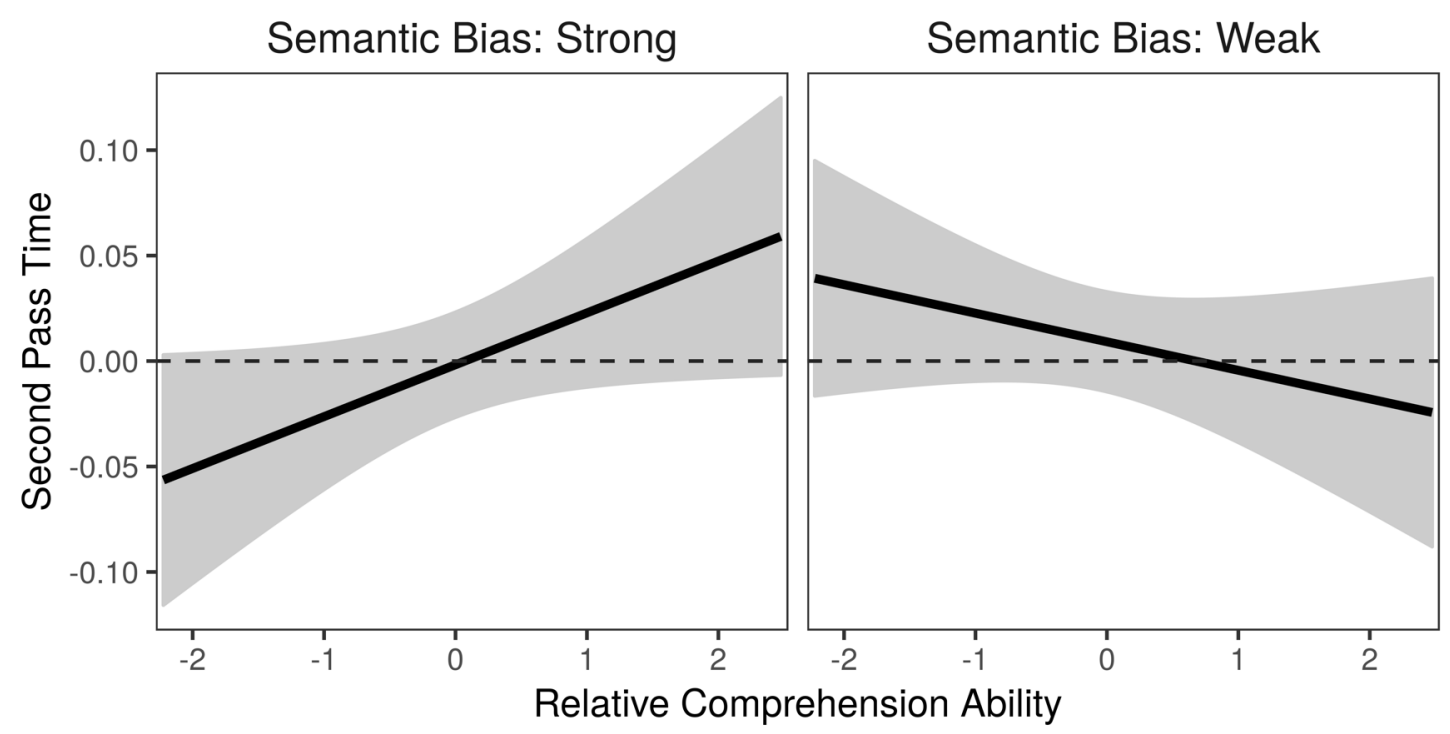

Figure 2. The estimated difference between coerced and control conditions as a function of RELATIVE COMPREHENSION ABILITY in second pass time at the VERB. Gray bands represent $95 \%$ confidence intervals. 


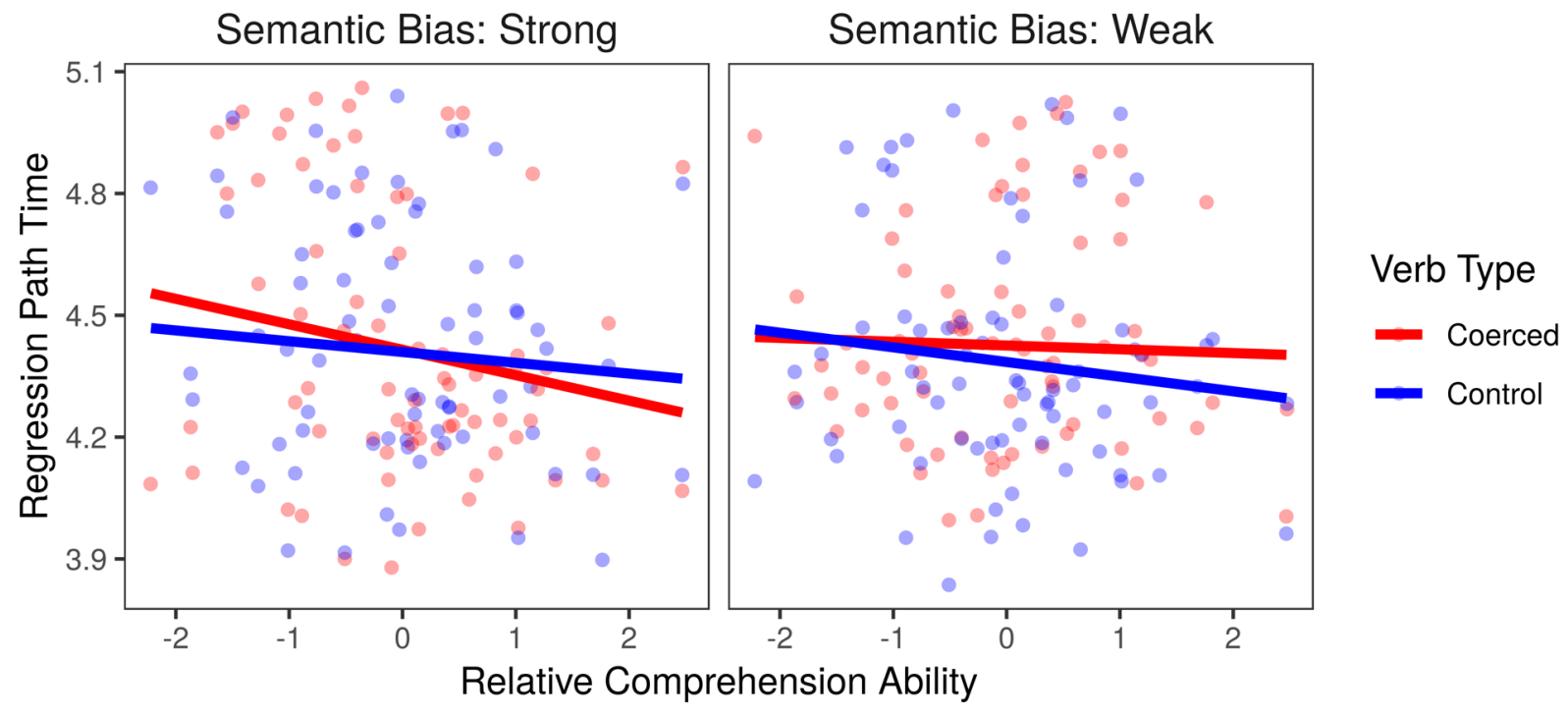

Figure 3. The interaction of ReLATIVE COMPREHENSION ABILITY, VERB TyPE, and SEMANTIC BIAS in regression path duration at the NOUN. Reading times are approximately log transformed. 


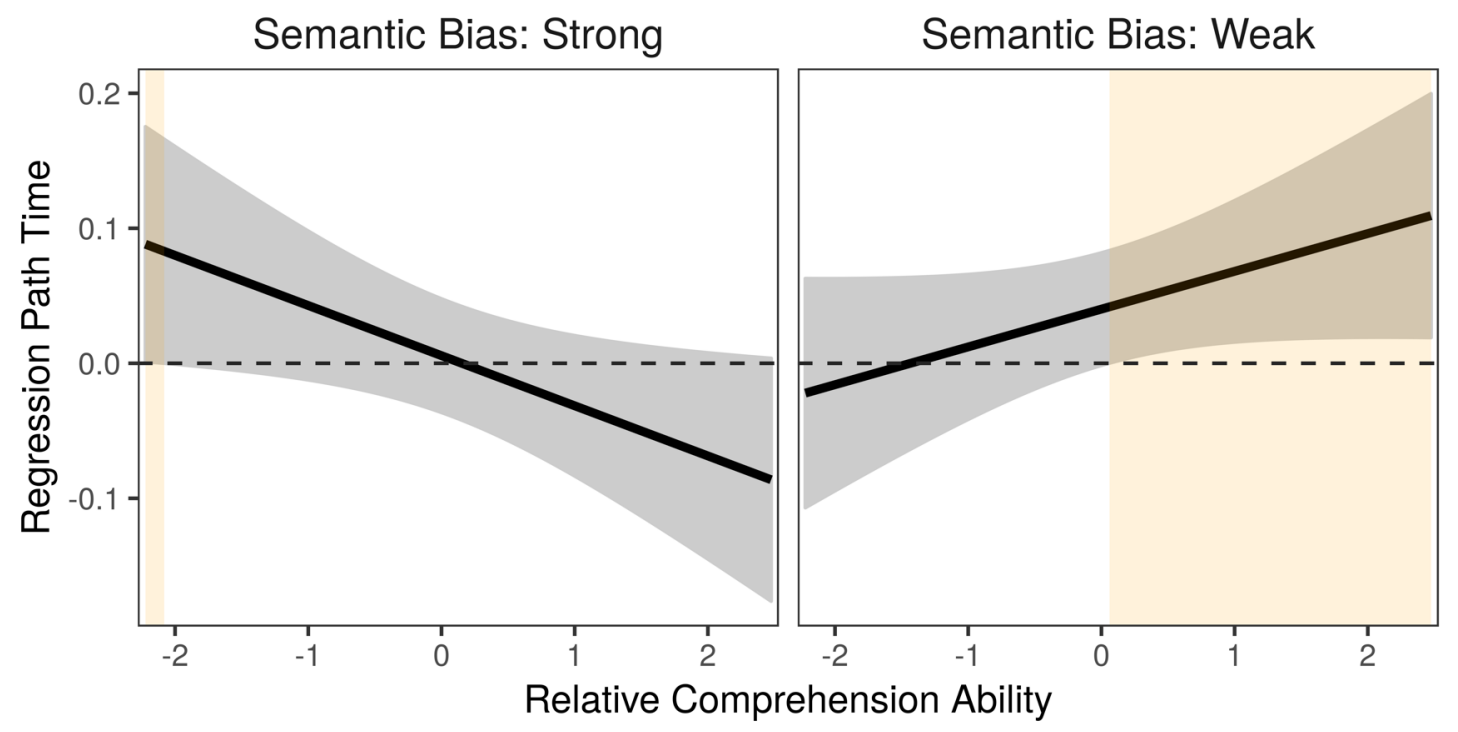

Figure 4. The estimated difference between coerced and control conditions as a function of RELATIVE COMPREHENSION ABILITY in log regression path duration at the NOUN. A coercion cost, showing greater reading time for coerced conditions, is highlighted in yellow in both panels. Gray bands represent $95 \%$ confidence intervals. 
INDIVIDUAL DIFFERENCES IN SEMANTIC PROCESSING

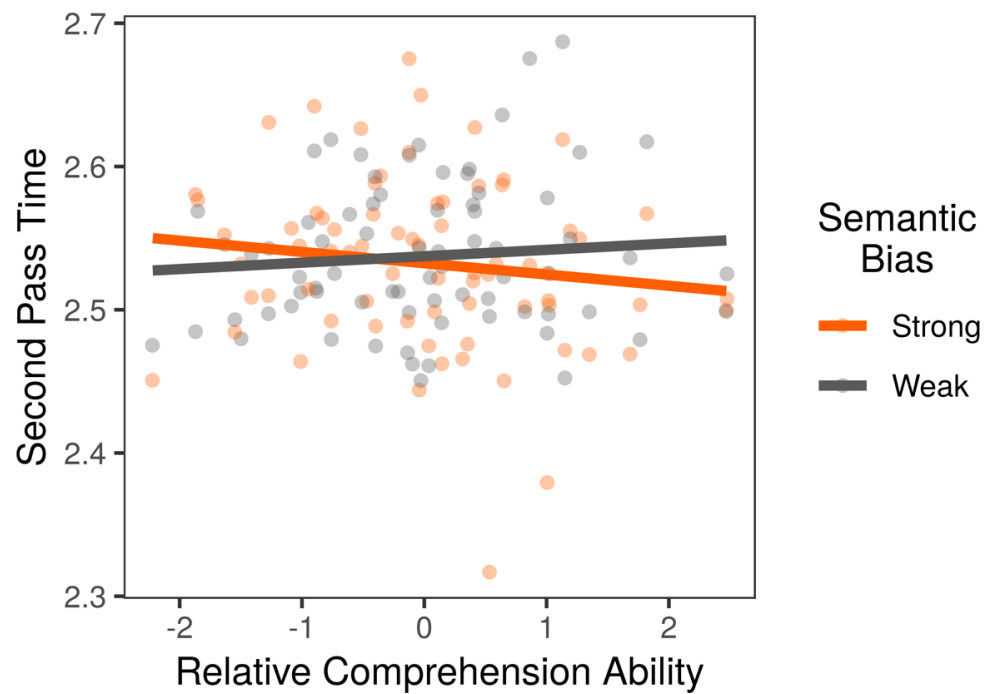

Figure 5. Comprehension AbILITy interacts with SEMANTIC BIAS in second as time at the NOUN. Reading times are reciprocal cube root transformed. 


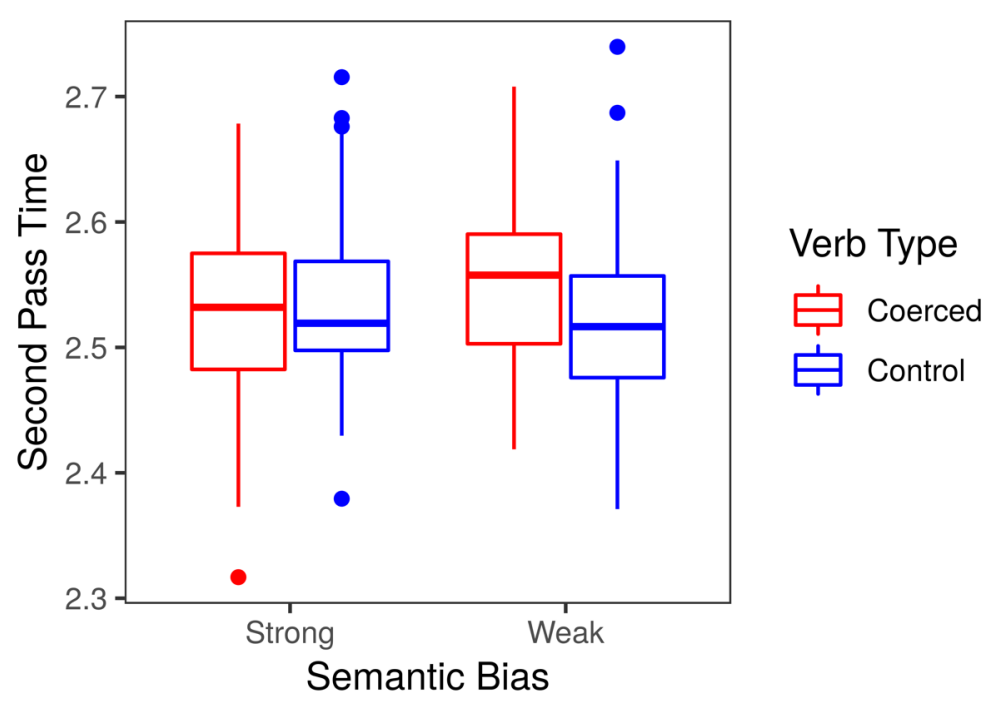

Figure 6. The interaction of SEMANTIC BIAS and VERB TYPE in second pass time at the NOUN. Reading times are reciprocal cube root transformed. 


\section{INDIVIDUAL DIFFERENCES IN SEMANTIC PROCESSING}

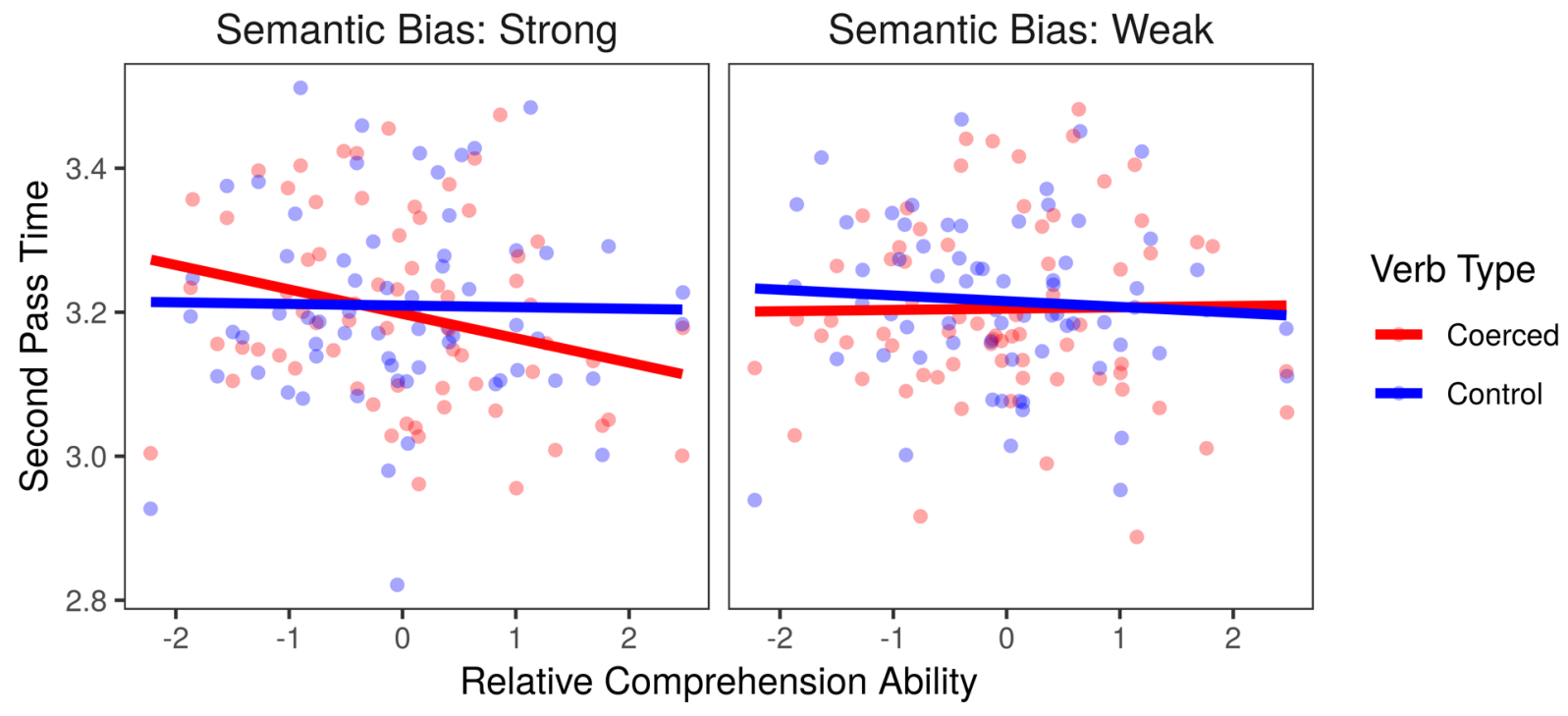

Figure 7. The interaction of RELATIVE COMPREHENSION ABILITY, VERB TYPE, and SEMANTIC BIAS in second pass time in the SPILLOVER region. Reading times are reciprocal fourth root transformed. 


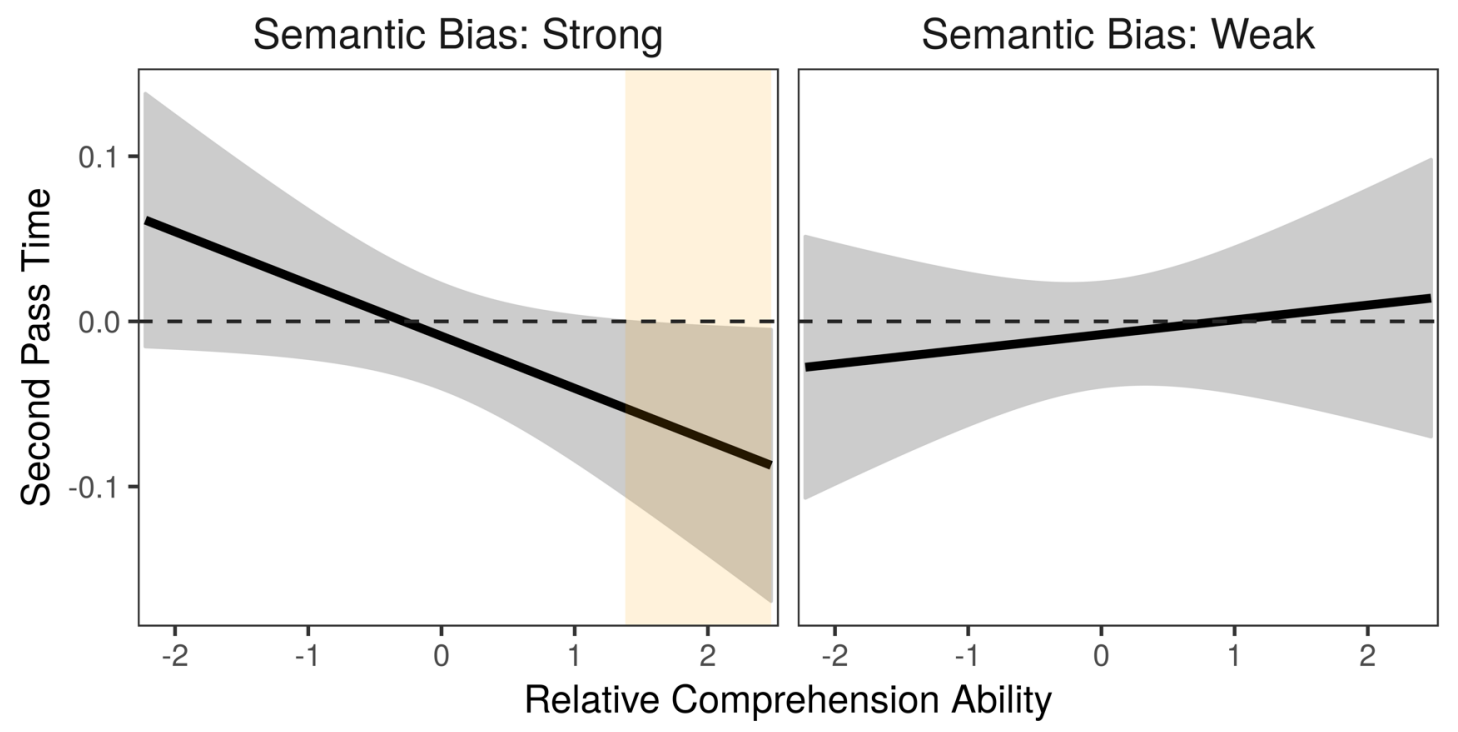

Figure 8. The estimated difference between coerced and control conditions as a function of RELATIVE COMPREHENSION ABILITY in second pass time in the SPILLOVER region. The highlighted portion of the left panel suggests that relatively skilled comprehenders re-read strongly biased coerced expressions more quickly than control sentences in this region. Gray bands represent $95 \%$ confidence intervals. 


\section{INDIVIDUAL DIFFERENCES IN SEMANTIC PROCESSING}

Appendix A: Model selection

We determined the appropriate random effects structure for each model via a model selection procedure, rather than following the more common "keep it maximal" heuristic (i.e., defaulting to maximal random effects structures, an approach typically attributed to Barr, Levy, Scheepers, \& Tily, 2013). As discussed by Matuschek and colleagues (Matuschek, Kliegl, Vasishth, Baayen, \& Bates, 2017), the heuristic maximal approach may have undesirable consequences, including a reduction in the power to detect effects (i.e., increased Type II error), and increased likelihood of models that, even if convergent, may nonetheless be degenerate (e.g., with invalid variance-covariance structures; see also Baayen, Vasishth, Kliegl, \& Bates, 2017; Bates, Kliegl, Vasishth, \& Baayen, 2015). Therefore, we used the RePsychLing package (Baayen, Bates, Kliegl, \& Vasishth, 2015) to determine the maximum number of random effects parameters supported by the data for each eye tracking measure in each scoring region. In each case, after identifying the appropriate random effects structure, we used likelihood ratio tests (LRTs) to compare the goodness of fit of the more parsimonious models with that of valid maximally-specified models (i.e., that converged and were not otherwise degenerate). All models include random intercepts (I) for both participants and items. Random slopes comprised SEMAnTiC COMPETition (S), VERB Type (V), and/or their interaction $(\mathrm{S} \times \mathrm{V})$. Models also included fixed effects of three nuisance covariates of no interest (DECODING, VOCABULARY, and LENGTH). No difference in model fit indicates that the more parsimonious model should be preferred. Details of the model selection procedure, including the random effects structure used for each model and the associated chi-square $\left(\chi^{2}\right)$ statistic from the LRT (which indexes whether the difference in fit between models is significant), are presented in Tables A1 (Verb scoring region), A2 (Noun scoring region), and A3 (Spillover scoring region). For all models, all parsimonious models fit the data as well as the maximal models. 


\begin{tabular}{|c|c|c|c|c|c|c|c|}
\hline $\begin{array}{l}\text { FIXED EFFECTS } \\
(\mathrm{S} \times \mathrm{V} \times \mathrm{RCA})\end{array}$ & $\begin{array}{l}\text { RANDOM } \\
\text { EFFECTS }\end{array}$ & $\begin{array}{c}\text { MAXIMAL } \\
\text { MODEL }\end{array}$ & $\begin{array}{l}\text { LOG } \\
\text { LIK }\end{array}$ & $\begin{array}{c}\text { PARSIMONIOUS } \\
\text { MODEL }\end{array}$ & $\begin{array}{l}\text { LOG } \\
\text { LIK }\end{array}$ & $\chi^{2}$ & $p$ \\
\hline First pass time & $\begin{array}{r}\text { Participants } \\
\text { Items }\end{array}$ & $\begin{array}{l}\mathrm{I}+\mathrm{S}, \mathrm{V} \\
\mathrm{I}+\mathrm{S}, \mathrm{V}, \mathrm{S} \times \\
\mathrm{V}\end{array}$ & 775.03 & $\begin{array}{l}\mathrm{I} \\
\mathrm{I}+\mathrm{S}, \mathrm{V}, \mathrm{S} \times \mathrm{V}\end{array}$ & 771.22 & 7.613 & .179 \\
\hline Regression path & $\begin{array}{r}\text { Participants } \\
\text { Items }\end{array}$ & $\begin{array}{l}\mathrm{I}+\mathrm{S}, \mathrm{V}, \mathrm{S} \times \\
\mathrm{V} \\
\mathrm{I}+\mathrm{S}, \mathrm{V}, \mathrm{S} \times \\
\mathrm{V}\end{array}$ & $\mathrm{n} / \mathrm{a}$ & $\begin{array}{l}\mathrm{I}+\mathrm{S}, \mathrm{V}, \mathrm{S} \times \mathrm{V} \\
\mathrm{I}+\mathrm{S}, \mathrm{V}, \mathrm{S} \times \mathrm{V}\end{array}$ & $\mathrm{n} / \mathrm{a}$ & & \\
\hline Second pass time & $\begin{array}{r}\text { Participants } \\
\text { Items }\end{array}$ & $\begin{array}{l}\mathrm{I}+\mathrm{S}, \mathrm{V} \\
\mathrm{I}+\mathrm{S}, \mathrm{V}, \mathrm{S} \times \\
\mathrm{V}\end{array}$ & 593.88 & $\begin{array}{l}\text { I } \\
\text { I }\end{array}$ & 591.40 & 4.966 & .986 \\
\hline Total time & $\begin{array}{r}\text { Participants } \\
\text { Items }\end{array}$ & $\begin{array}{l}\mathrm{I}+\mathrm{S}, \mathrm{V}, \mathrm{S} \times \\
\mathrm{V} \\
\mathrm{I}+\mathrm{S}, \mathrm{V}, \mathrm{S} \times \\
\mathrm{V}\end{array}$ & -1011.9 & $\begin{array}{l}\mathrm{I}+\mathrm{S}, \mathrm{V} \\
\mathrm{I}+\mathrm{S}, \mathrm{V}\end{array}$ & -1015.4 & 6.907 & .547 \\
\hline
\end{tabular}

Table A1. Model selection for the VERB scoring region.

\begin{tabular}{|c|c|c|c|c|c|c|c|}
\hline $\begin{array}{l}\text { FIXED EFFECTS } \\
(\mathrm{S} \times \mathrm{V} \times \mathrm{RCA})\end{array}$ & $\begin{array}{l}\text { RANDOM } \\
\text { EFFECTS }\end{array}$ & $\begin{array}{c}\text { MAXIMAL } \\
\text { MODEL }\end{array}$ & $\begin{array}{l}\text { LOG } \\
\text { LIK }\end{array}$ & $\begin{array}{c}\text { PARSIMONIOUS } \\
\text { MODEL } \\
\end{array}$ & $\begin{array}{l}\text { LOG } \\
\text { LIK }\end{array}$ & $\chi^{2}$ & $p$ \\
\hline \multirow[t]{2}{*}{ First pass time } & Participants & $\begin{array}{l}\mathrm{I}+\mathrm{S}, \mathrm{V}, \mathrm{S} \times \\
\mathrm{V}\end{array}$ & -1903.3 & $\mathrm{I}+\mathrm{V}$ & -1907.1 & 7.588 & .750 \\
\hline & Items & $\begin{array}{l}\mathrm{I}+\mathrm{S}, \mathrm{V}, \mathrm{S} \times \\
\mathrm{V}\end{array}$ & & $\mathrm{I}+\mathrm{S}, \mathrm{V}$ & & & \\
\hline Regression path & $\begin{array}{r}\text { Participants } \\
\text { Items }\end{array}$ & $\begin{array}{l}\mathrm{I}+\mathrm{S}, \mathrm{V} \\
\mathrm{I}+\mathrm{S}, \mathrm{V}, \mathrm{S} \times \\
\mathrm{V}\end{array}$ & -359.3 & $\begin{array}{l}\mathrm{I}+\mathrm{S} \\
\mathrm{I}+\mathrm{S}, \mathrm{V}, \mathrm{S} \times \mathrm{V}\end{array}$ & -360.1 & 1.518 & .678 \\
\hline \multirow[t]{2}{*}{ Second pass time } & Participants & $\begin{array}{l}\mathrm{I}+\mathrm{S}, \mathrm{V}, \mathrm{S} \times \\
\mathrm{V}\end{array}$ & 920.6 & $\mathrm{I}+\mathrm{V}$ & 918 & 5.078 & .985 \\
\hline & Items & $\begin{array}{l}\mathrm{I}+\mathrm{S}, \mathrm{V}, \mathrm{S} \times \\
\mathrm{V}\end{array}$ & & $\mathrm{I}+\mathrm{S}$ & & & \\
\hline \multirow[t]{2}{*}{ Total time } & Participants & $\begin{array}{l}\mathrm{I}+\mathrm{S}, \mathrm{V}, \mathrm{S} \times \\
\mathrm{V}\end{array}$ & -2451.9 & $\mathrm{I}+\mathrm{V}$ & -2453.1 & 2.508 & .927 \\
\hline & Items & $\begin{array}{l}\mathrm{I}+\mathrm{S}, \mathrm{V}, \mathrm{S} \times \\
\mathrm{V}\end{array}$ & & $\mathrm{I}+\mathrm{S}, \mathrm{V}, \mathrm{S} \times \mathrm{V}$ & & & \\
\hline
\end{tabular}

\section{Table A2. Model selection for the NOUN scoring region.}




\begin{tabular}{|c|c|c|c|c|c|c|c|}
\hline $\begin{array}{l}\text { FIXED EFFECTS } \\
(\mathrm{S} \times \mathrm{V} \times \mathrm{RCA})\end{array}$ & $\begin{array}{l}\text { RANDOM } \\
\text { EFFECTS }\end{array}$ & $\begin{array}{c}\text { MAXIMAL } \\
\text { MODEL }\end{array}$ & $\begin{array}{l}\text { LOG } \\
\text { LIK }\end{array}$ & $\begin{array}{c}\text { PARSIMONIOUS } \\
\text { MODEL }\end{array}$ & $\begin{array}{l}\text { LOG } \\
\text { LIK }\end{array}$ & $\chi^{2}$ & $p$ \\
\hline \multirow[t]{2}{*}{ First pass time } & Participants & $\begin{array}{l}\mathrm{I}+\mathrm{S}, \mathrm{V}, \mathrm{S} \times \\
\mathrm{V}\end{array}$ & -219.22 & $\mathrm{I}+\mathrm{S}$ & -221 & 3.566 & .998 \\
\hline & Items & $\begin{array}{l}\mathrm{I}+\mathrm{S}, \mathrm{V}, \mathrm{S} \times \\
\mathrm{V}\end{array}$ & & $\mathrm{I}+\mathrm{S}$ & & & \\
\hline Regression path & $\begin{array}{r}\text { Participants } \\
\text { Items }\end{array}$ & $\begin{array}{l}\mathrm{I}+\mathrm{S}, \mathrm{V} \\
\mathrm{I}+\mathrm{S}, \mathrm{V}, \mathrm{S} \times \\
\mathrm{V}\end{array}$ & -11405 & $\begin{array}{l}\mathrm{I}+\mathrm{S}, \mathrm{V} \\
\mathrm{I}+\mathrm{S}\end{array}$ & -11407 & 3.090 & .979 \\
\hline \multirow[t]{2}{*}{ Second pass time } & Participants & $\begin{array}{l}\mathrm{I}+\mathrm{S}, \mathrm{V}, \mathrm{S} \times \\
\mathrm{V}\end{array}$ & -736.86 & $\mathrm{I}+\mathrm{V}$ & -732.05 & 4.809 & .964 \\
\hline & Items & $\mathrm{I}+\mathrm{S}, \mathrm{V}$ & & I & & & \\
\hline Total time & $\begin{array}{r}\text { Participants } \\
\text { Items }\end{array}$ & $\begin{array}{l}\mathrm{I}+\mathrm{S}, \mathrm{V} \\
\mathrm{I}+\mathrm{S}, \mathrm{V}, \mathrm{S} \times \\
\mathrm{V}\end{array}$ & -1440 & $\begin{array}{l}\mathrm{I}+\mathrm{V} \\
\mathrm{I}+\mathrm{S}, \mathrm{V}\end{array}$ & -1443 & 6.018 & .538 \\
\hline
\end{tabular}


Appendix B: Estimating differences between experimental conditions along a continuous variable

The differences between coerced and control conditions as a function of relative Comprehension Ability and their confidence intervals (Figures 2, 4, and 8 in the article) were estimated using the plot_diff function from the R package itsadug (version 2.3; van Rij, Wieling, Baayen, \& van Rijn, 2017). This method has already been successfully used for a variety of applications, such as estimating the time intervals of significant differences between conditions in eye tracking research (e.g., Heyselaar, Peeters, \& Hagoort, 2018; Wieling, 2018). As the input required by the plot_diff function is a GAM object, we first refitted the final lmer models using the gam function from the mgev package (version 1.8-27; Wood, 2011), then we used the plot_diff function to generate the figures. An example analysis with accompanying R code is reported below.

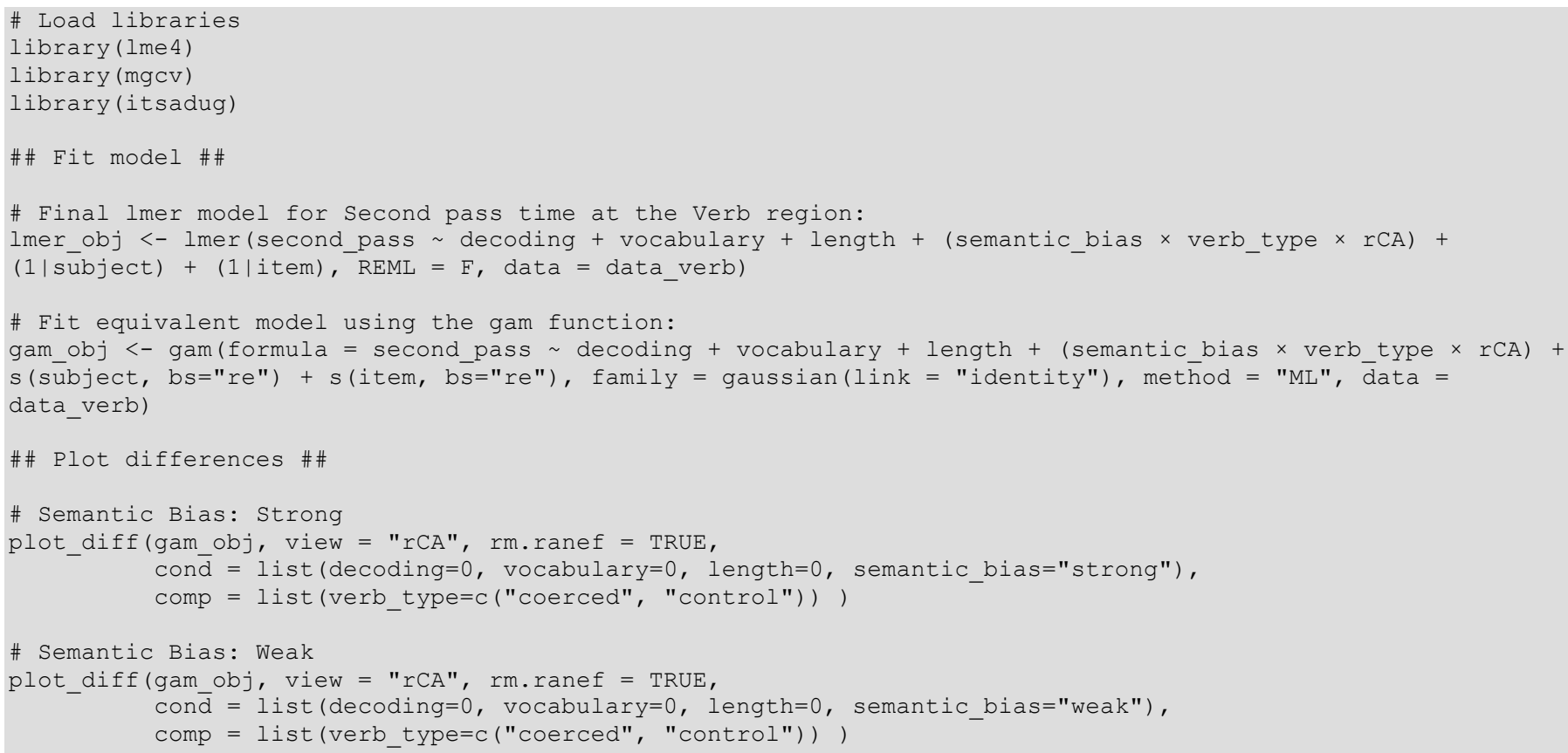

